\title{
Measuring acetic and formic acid by proton-transfer-reaction mass spectrometry: sensitivity, humidity dependence, and quantifying interferences
}

\author{
M. Baasandorj ${ }^{1}$, D. B. Millet ${ }^{1}$, L. Hu ${ }^{1, *}$, D. Mitroo ${ }^{2}$, and B. J. Williams ${ }^{2}$ \\ ${ }^{1}$ University of Minnesota, St. Paul, MN 55108, USA \\ ${ }^{2}$ Washington University in St. Louis, St. Louis, MO 63130, USA \\ *now at: Harvard University, Cambridge, MA 02138, USA
}

Correspondence to: D. B. Millet (dbm@umn.edu)

Received: 5 September 2014 - Published in Atmos. Meas. Tech. Discuss.: 31 October 2014

Revised: 29 January 2015 - Accepted: 12 February 2015 - Published: 18 March 2015

\begin{abstract}
We present a detailed investigation of the factors governing the quantification of formic acid (FA), acetic acid (AA), and their relevant mass analogues by proton-transferreaction mass spectrometry (PTR-MS), assess the underlying fragmentation pathways and humidity dependencies, and present a new method for separating FA and AA from their main isobaric interferences. PTR-MS sensitivities towards glycolaldehyde, ethyl acetate, and peroxyacetic acid at $m / z 61$ are comparable to that for AA; when present, these species will interfere with ambient AA measurements by PTR-MS. Likewise, when it is present, dimethyl ether can interfere with FA measurements. For a reduced electric field $(E / N)$ of 125 Townsend (Td), the PTR-MS sensitivity towards ethanol at $m / z \quad 47$ is 5-20 times lower than for FA; ethanol will then only be an important interference when present in much higher abundance than FA. Sensitivity towards 2-propanol is $<1 \%$ of that for AA, so that propanols will not in general represent a significant interference for AA. Hydrated product ions of AA, glycolaldehyde, and propanols occur at $m / z 79$, which is also commonly used to measure benzene. However, the resulting interference for benzene is only significant when $E / N$ is low ( $\lesssim 100 \mathrm{Td}$ ). Addition of water vapor affects the PTR-MS response to a given compound by (i) changing the yield for fragmentation reactions and (ii) increasing the importance of ligand switching reactions. In the case of AA, sensitivity to the molecular ion increases with humidity at low $E / N$ but decreases with humidity at high $E / N$ due to water-driven fragmentation. Sensitivity towards FA decreases with humidity throughout the full range of $E / N$. For glycolaldehyde and the alcohols, the
\end{abstract}

sensitivity increases with humidity due to ligand switching reactions (at low $E / N$ ) and reduced fragmentation in the presence of water (at high $E / N$ ). Their role as interferences will typically be greatest at high humidity. For compounds such as AA where the humidity effect depends strongly on the collisional energy in the drift tube, simple humidity correction factors $\left(X_{\mathrm{R}}\right)$ will only be relevant for a specific instrumental configuration. We recommend $E / N \sim 125 \mathrm{Td}$ as an effective condition for AA and FA measurements by PTRMS, as it optimizes between the competing $E / N$-dependent mechanisms controlling their sensitivities and those of the interfering species. Finally, we present the design and evaluation of an online acid trap for separating AA and FA from their interfering species at $m / z 61$ and 47, and we demonstrate its performance during a field deployment to St. Louis, USA, during August-September of 2013.

\section{Introduction}

Formic acid $(\mathrm{HCOOH}, \mathrm{FA})$ and acetic acid $\left(\mathrm{CH}_{3} \mathrm{COOH}\right.$, AA) are among the most abundant volatile organic compounds (VOCs) in the atmosphere. They are present in significant amounts across a wide range of environments, including marine, continental, urban, and remote atmospheres (Chebbi and Carlier, 1996; Keene and Galloway, 1984). They are a major source of acidity in precipitation, particularly in unpolluted locations, and impact the chemistry of fog and cloud water (Andreae et al., 1988; Galloway et al., 1982; 
Keene and Galloway, 1984; Keene et al., 1983). The predominant source of FA and AA is thought to be photochemical degradation of biogenic VOCs, in particular isoprene and its oxidation products (Chebbi and Carlier, 1996; Paulot et al., 2011). Other sources include oxidation of anthropogenic and pyrogenic VOCs (Hatakeyama et al., 1986; Paulot et al., 2011) and direct emissions from biomass and biofuel burning (Akagi et al., 2011; Yokelson et al., 2009) and terrestrial vegetation (Kesselmeier et al., 1998; Kesselmeier and Staudt, 1999). However, the magnitudes of these sources are highly uncertain, and current models severely underestimate the observed atmospheric concentrations of FA and AA, implying the existence of one or more large missing sources (Le Breton et al., 2014; Paulot et al., 2011; Stavrakou et al., 2012). Atmospheric measurements of organic acids across different environments, preferably with high time resolution, are needed to elucidate their sources and improve our understanding of these species and their impacts.

Early measurements of FA and AA relied on offline sample collection methods. Ambient formic and acetic acid samples were collected using $\mathrm{KOH}$-coated $\mathrm{C}_{18}$ cartridges (Grosjean, 1991, 1992), aqueous scrubber/mist chamber techniques (Andreae et al., 1988; Talbot et al., 1988; Talbot et al., 1999), or $\mathrm{Na}_{2} \mathrm{CO}_{3}$-coated cellulose filters/high-volume samplers (Glasius et al., 2001) and were analyzed by liquid chromatography-ultraviolet detection (Grosjean, 1991, 1992), high-performance liquid chromatography with conductivity detection (Glasius et al., 2001), or ion-exchange chromatography (Andreae et al., 1988; Keene and Galloway, 1984; Keene et al., 1983; Talbot et al., 1988, 1999). In recent years, chemical-ionization mass spectrometry (CIMS) has emerged as a powerful tool for selective and rapid measurements of many atmospheric trace gases (Huey, 2007). Bertram et al. (2011), Roberts et al. (2010), Roberts et al. (2011), Veres et al. (2008), and Veres et al. (2010) showed that CIMS can be utilized to detect gas-phase organic acids with high time resolution and high sensitivity. Veres et al. (2008) employed negative-ion proton-transfer chemicalionization mass spectrometry (NI-PT-CIMS) with the acetate ionization scheme to quantify FA and higher organic acids (but not AA). Le Breton et al. $(2012,2014)$ reported airborne CIMS measurements of formic acid using an $I^{-}$ionization scheme. Recently, a CIMS measurement that resolves the functional isomers acetic acid and glycolaldehyde based on a $\mathrm{CF}_{3} \mathrm{O}^{-}$ionization scheme has been reported (Clair et al., 2014).

Proton-transfer-reaction mass spectrometry (PTR-MS), also a chemical ionization technique, allows simultaneous detection of a broad range of VOCs with high sensitivity and fast time response (de Gouw and Warneke, 2007). PTR-MS is widely used for measurements of environmental VOCs on a diverse array of platforms (e.g., Beale et al., 2013; de Gouw et al., 2003; Eerdekens et al., 2009; Hu et al., 2013; Kolb et al., 2004; Park et al., 2013; Paulot et al., 2011; Wang et al., 2009; Williams et al., 2004). The instrument performance, response, and specificity are well characterized for many atmospherically important VOCs (de Gouw and Warneke, 2007). However, the versatility of the PTR-MS technique for measuring a wide ensemble of VOCs comes at the cost of chemical detail (de Gouw and Warneke, 2007; Lindinger et al., 1998), as all compounds with a proton affinity higher than $\mathrm{H}_{2} \mathrm{O}$ will be detected at any given mass-to-charge ratio.

FA and AA measurements by PTR-MS have been reported in a number of previous studies (de Gouw and Warneke, 2007; Feilberg et al., 2010; Haase et al., 2012; Jardine et al., 2011; C. Jordan et al., 2009; Karl et al., 2004; Lee et al., 2006a; Warneke et al., 2004). However, a number of critical issues involving instrument response and specificity remain to be resolved as discussed below. Given the large worldwide user base for PTR-MS, enabling robust and accurate AA and FA measurements by this technique is a key step towards increasing the data coverage for atmospheric carboxylic acids and their precursors and a better understanding of their budgets.

Only a few of the previous CIMS-based studies of FA and AA reported direct calibrations to quantify the instrument response for these compounds in the field (Haase et al., 2012; Lee et al., 2006a; Veres et al., 2008, 2011) due to the difficulty of producing reliable gas-phase standards (de Gouw and Warneke, 2007). In addition, there are contradictory reports in the literature on the humidity dependence of PTRMS sensitivity for AA. Haase et al. (2012) and Warneke et al. (2001) found no significant humidity dependence for AA. However, Feilberg et al. (2010) found that the extent of fragmentation of protonated AA (mass-to-charge ratio, $\mathrm{m} / \mathrm{z}$ 61 ) in the PTR-MS drift tube, which leads to a fragment ion at $m / z 43$, varied significantly with ambient humidity. While the sum of the ions detected at $m / z, 61$ and $m / z 43$ was independent of humidity (Feilberg et al., 2010), many other species are detected at $m / z, 43$ (de Gouw and Warneke, 2007), and this sum will not be unique for AA in the field. Determining the fragmentation patterns and humidity dependence of PTR-MS sensitivity for both FA and AA is therefore needed for accurate interpretation of the mass spectra.

The degree of PTR-MS specificity for AA and FA is another issue that needs to be addressed. Protonated AA and FA are detected at unit masses 61 and 47, respectively, with PTRMS. However, multiple other species including glycolaldehyde, propanols, ethyl acetate (Fortner et al., 2009; Haase et al., 2012), and peroxyacetic acid (PAA) (Spanel et al., 2003) can potentially interfere with PTR-MS measurements of AA at $m / z$ 61. Glycolaldehyde and propanols (1-propanol, 2propanol) have the same nominal molecular weight as AA, while ethyl acetate and peroxyacetic acid are known to fragment in the PTR-MS drift tube upon protonation, resulting in a fragment ion detected at $m / z 61$ (Fortner et al., 2009; Spanel et al., 2003). In the case of FA, ethanol and dimethyl ether (DME) can also be detected at unit $\mathrm{m} / \mathrm{z} 47$ (Veres et al., 2008). Some of the above compounds are only nominally isobaric with FA or AA (e.g., propanols, ethanol, DME) and 
thus represent interferences when using a quadrupole PTRMS; but can potentially be resolved using a high-resolution time-of-flight mass spectrometer (Blake et al., 2009; A. Jordan et al., 2009). Others (e.g., glycolaldehyde and the fragment ions from ethyl acetate and peroxyacetic acid) are isomeric with the target analyte and thus cannot be separated based on exact mass.

In this paper we present a detailed investigation of the factors governing the PTR-MS response to AA and FA. We quantify the instrumental response to AA, FA, and their respective mass analogues as a function of $E / N$ (the ratio of the electric field to gas number density in the PTR-MS drift tube) and humidity, and assess how these factors impact the sensitivity, specificity, and stability of carboxylic acid measurements by PTR-MS. We examine the fragmentation patterns for the various isobaric compounds and describe the various reaction mechanisms governing the ion chemistry of $\mathrm{H}_{3} \mathrm{O}^{+}$with the protonated acids $\left(\mathrm{CH}_{3} \mathrm{COOH}-\mathrm{H}^{+}\right.$and $\mathrm{HCOOH}-\mathrm{H}^{+}$). We present a novel acid trap for separating FA and AA from the various isobaric species detected at mass 61 and 47 and demonstrate its performance. Finally we present some example PTR-MS measurements of AA, FA, and glycolaldehyde from a field deployment to St. Louis, USA, during August-September of 2013 and discuss the extent and variability of interferences for AA and FA measurements by PTR-MS in an urban region impacted by biogenic emissions.

\section{Experimental design and performance}

In this section we describe the experimental setup used in this study, presenting results in the following order: (1) PTR-MS and inlet system; (2) memory effects; (3) description and validation of the acid calibration system; (4) effects of humidity and $E / N$ on the PTR-MS response for AA, FA, glycolaldehyde, ethyl acetate, 2-propanol, DME, and ethanol; (5) reaction mechanisms governing the ion chemistry for these species; (6) role of interferences; and (7) separation of the isobaric species in the laboratory and field.

\subsection{PTR-MS and inlet system}

A high-sensitivity quadrupole PTR-MS from Ionicon Analytik (Innsbruck, Austria) was employed for this study. The PTR-MS instrument has previously been described in detail by Lindinger et al. (1998) and de Gouw and Warneke (2007). It consists of an ion source to produce $\mathrm{H}_{3} \mathrm{O}^{+}$ions, a drift tube where proton transfer reactions between $\mathrm{H}_{3} \mathrm{O}^{+}$and VOCs take place, and a quadrupole mass spectrometer. Trace gases with proton affinities higher than that of water (166.5 kcal mol${ }^{-1}$; de Gouw and Warneke, 2007) are ionized via proton transfer reaction with $\mathrm{H}_{3} \mathrm{O}^{+}$in the drift tube ( $9.2 \mathrm{~cm}$ long) and mass separated and detected by the quadrupole mass spectrometer. AA and FA, with proton affinities of 187.3 and $177.3 \mathrm{kcal} \mathrm{mol}^{-1}$, respectively (Hunter and Lias, 1998), undergo proton transfer and are detected at protonated $m / z$ ratios of 61 and 47 .

The gas inlet system for the PTR-MS instrument is as discussed in our previous papers ( $\mathrm{Hu}$ et al., 2013; Hu et al., 2011), with modifications described below for measuring carboxylic acids. The inlet system is designed to subsample a flow of $\sim 1000 \mathrm{sccm}$ through $3 \mathrm{~m}$ of $1 / 2^{\prime \prime}$ OD PFA tubing followed by $1 \mathrm{~m}$ of $1 / 4^{\prime \prime}$ OD PFA tubing. Of this, $\sim 35$ sccm is sent to the PTR-MS via $1 \mathrm{~m}$ of $1 / 8^{\prime \prime}$ PFA tubing. Zero air for instrument calibrations and blanks is generated by passing ambient air through a catalytic converter containing platinum bead catalyst $(0.5 \%, 3 \mathrm{~mm}$; Shimadzu Corp.) and heated to $400{ }^{\circ} \mathrm{C}$. The water flow rate was maintained at $6.5 \mathrm{sccm}$, and averaging times for the subject species were varied between 2 and $10 \mathrm{~s}$ for the results presented here.

\subsection{Memory effects for AA and FA}

The inlet system is constructed such that the incoming air sample is only exposed to PFA and PTFE surfaces, which have both been found to cause minimal adsorption of VOCs (de Gouw and Warneke, 2007; Hu et al., 2011; Schnitzhofer et al., 2009). Nonetheless, with our original setup we found that the disappearance times for AA and FA (initially $\sim 20$ $25 \mathrm{~min}$ ) were both significantly reduced when we diverted the air sample through a hydrocarbon trap immediately upstream of the PTR-MS, suggesting memory effects that were mostly due to adsorption outside the PTR-MS instrument.

To address this issue, all inlet, calibration, and sampling lines were heated to $\sim 50^{\circ} \mathrm{C}$ using a self-regulated heating tape wrapped in an insulating jacket, and all dead volume in our inlet, calibration, and sample delivery system was minimized. Quantitative delivery of the acids through sampling and calibration lines and the overall inlet system was verified by passing a known amount of acid through the apparatus. With the above adjustments, the disappearance times for AA and FA (more than four e-folding times) for the entire inlet/PTR-MS apparatus decreased significantly to approximately 4 and $8 \mathrm{~min}$, respectively, shorter than has been reported previously (Haase et al., 2012).

\subsection{Permeation-based VOC calibration system and its validation}

The calibration system is based on the design of Veres et al. (2010) and consists of a temperature-controlled aluminum permeation tube housing, a catalytic converter filled with $\mathrm{Pt}$ catalyst $\left(0.5 \%, 3 \mathrm{~mm}\right.$; Shimadzu Corp.) held at $350{ }^{\circ} \mathrm{C}$, and a non-dispersive infrared $\mathrm{CO}_{2}$ detector (LICOR 840A). Four $3 / 8^{\prime \prime}$ PFA tubing sleeves pass through the heated block and house the permeation devices. Each permeation tube housing and the catalytic converter are purged with a constant flow of ultra pure air $(10 \mathrm{sccm})$ maintained with a mass flow controller. The temperature of the permeation housing is varied between 34 and $45^{\circ} \mathrm{C}$. We use uncertified permeation tubes 
from VICI (Valco Instruments Co., Inc.) as well as custom units made in our laboratory from $1 / 4^{\prime \prime}$ PFA tubing and teflon plugs. Calibrations are performed following at least $10 \mathrm{~h}$ of equilibration at a given temperature. The VOC concentration in the calibration stream is quantified by oxidizing it to $\mathrm{CO}_{2}$ in the catalytic converter and measuring the resulting $\mathrm{CO}_{2}$ concentration with the LICOR 840A. Complete oxidation is verified by scanning for residual VOCs with the PTR-MS. The calibration response was found to be independent of the flow rate through the system, suggesting minimal loss of carboxylic acids in the calibration apparatus.

Figure 1 shows sample $\mathrm{CO}_{2}$ temporal profiles obtained during background and calibration measurements of (a) $p$ xylene, (b) AA, and (c) FA. During a calibration, the flow from the permeation tube housing $(10 \mathrm{sccm})$ is sent through the catalytic converter for $40 \mathrm{~min}$. As the valves switch, the VOC $/ \mathrm{CO}_{2}$ rich air trapped inside the three way valves gives rise to an initial spike in the $\mathrm{CO}_{2}$ signal. After this initial spike, the $\mathrm{CO}_{2}$ signal stabilizes at a value corresponding to the amount of VOC oxidized in the catalytic converter. The longer equilibration time for the calibration system (15$20 \mathrm{~min})$ compared to the PTR-MS inlet system $(<1 \mathrm{~min})$ is due to the large difference in flow rates. Background $\mathrm{CO}_{2}$ levels measured before and after a calibration are consistently low and reproducible; the mean of these two measurements is used for background correction. In addition, VOC impurities in the carrier gas are quantified daily by sending a $10 \mathrm{sccm}$ carrier gas flow (with no VOC added) through the catalytic converter and measuring the resulting change in $\mathrm{CO}_{2}$ signal. During calibrations, $\mathrm{CO}_{2}$ mixing ratios generally vary between 3 and $8 \mathrm{ppm}$. Calibration of the LICOR 840A is performed monthly via dynamic dilution of a working $\mathrm{CO}_{2}$ standard $(210 \mathrm{ppm})$ traceable to the NOAA ESRL scale.

Following the second background $\mathrm{CO}_{2}$ measurement, the calibration stream is dynamically diluted and analyzed by the PTR-MS for 15 min to determine the instrumental sensitivity for the VOC of interest. VOC mixing ratios during these calibration runs are typically between 30 and $80 \mathrm{ppb}$. Past studies have demonstrated the linearity of PTR-MS sensitivity over concentrations ranging from sub-ppt to several tens of ppb (Beauchamp et al., 2013; de Gouw and Warneke, 2007; C. Jordan et al., 2009; Veres et al., 2010). PTR-MS background measurements are performed for $15 \mathrm{~min}$ prior to each calibration and are then applied to correct the ion signal. The PTR-MS sensitivity (ncps ppb ${ }^{-1}$ ) is then (de Gouw and Warneke, 2007):

Sensitivity $=\frac{I_{\mathrm{RH}^{+}}}{I_{\mathrm{H}_{3} \mathrm{O}^{+}} \times[R]} \times 10^{6}$,

where $I_{\mathrm{RH}^{+}}$is the background-corrected signal of $\mathrm{RH}^{+}$ions (cps) normalized to an $\mathrm{H}_{3} \mathrm{O}^{+}$signal $\left(I_{\mathrm{H}_{3} \mathrm{O}^{+}}\right)$of $10^{6} \mathrm{cps}$, and $[R]$ is the VOC concentration in ppb as determined by the $\mathrm{CO}_{2}$ calibration system.

The performance of the calibration system was validated using a dynamically diluted high-pressure premixed gas
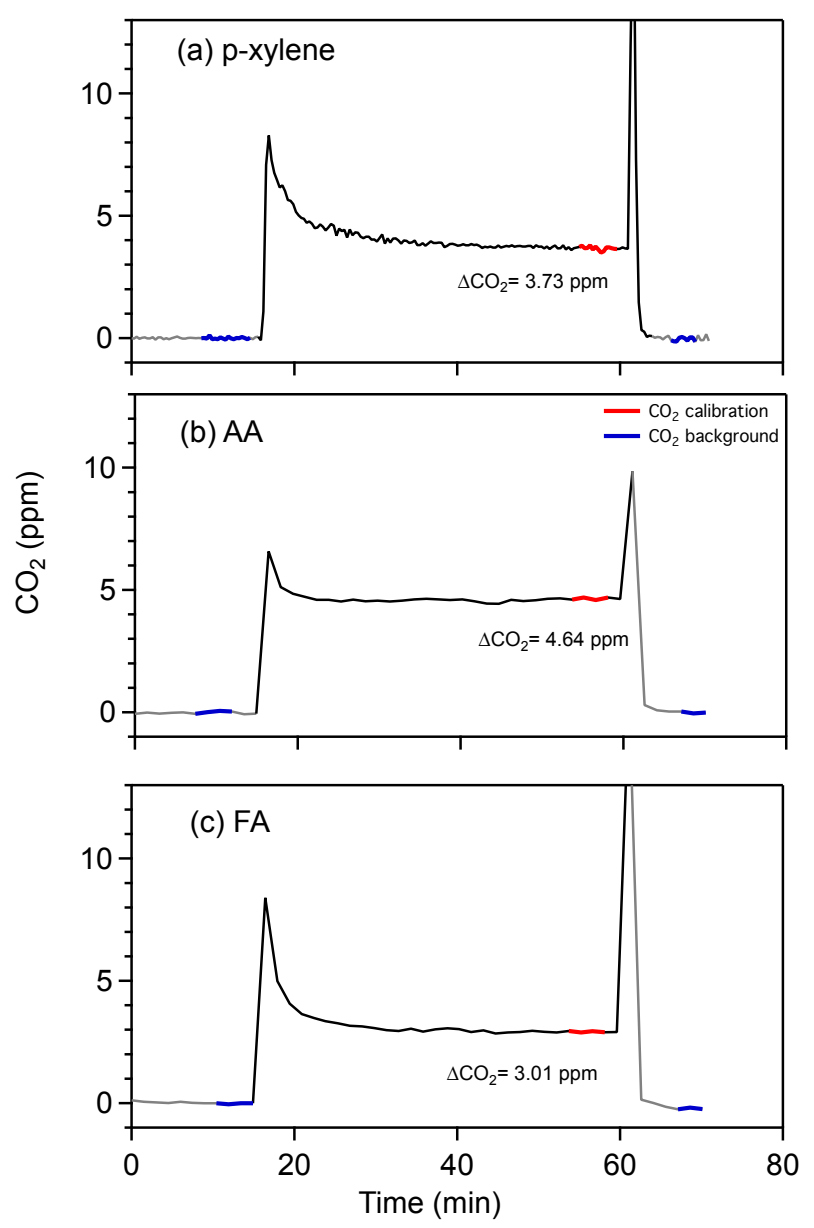

Figure 1. Example $\mathrm{CO}_{2}$ measurements obtained during calibration of (a) p-xylene, (b) acetic acid (AA), and (c) formic acid (FA). A $15 \mathrm{sccm}$ carrier gas flow containing a VOC from a temperaturecontrolled permeation source passes through a catalytic converter, and the resulting $\mathrm{CO}_{2}$ is then quantified using a non-dispersive infrared detector (LICOR 840A). Bypassing the catalytic converter enables a background measurement before and after each calibration. In this case, calibrated mixing ratios of 9.78, 49.1, and $61.04 \mathrm{ppb}$ were determined for $p$-xylene, AA, and FA in the PTR$\mathrm{MS}$ inlet system based on the corresponding $\mathrm{CO}_{2}$ increase $\left(\Delta \mathrm{CO}_{2}\right)$, the number of carbon atoms per molecule, and the downstream dilution factor.

cylinder containing known mixing ratios of $p$-xylene and acetone. Figure 2 shows a comparison between the concentrations determined using the calibration system and their nominal values based on the cylinder concentrations and dilution ratio. As shown in the figure, the two methods agree to within $5 \%$, demonstrating the reliability of the system in delivering an absolute calibration of chemicals across a wide range of vapor pressure. 
Table 1. PTR-MS sensitivities toward acetic acid (AA), formic acid (FA), and related species at $m / z$, 47 and $m / z 61$ as reported in the literature and in this study ${ }^{1}$.

\begin{tabular}{|c|c|c|c|c|c|c|}
\hline Compound & $\begin{array}{r}E / N, \\
\mathrm{Td}\end{array}$ & $\begin{array}{r}I_{\left(\mathrm{H}_{2} \mathrm{O}\right)-\mathrm{H}_{3} \mathrm{O}+}: \\
\quad I_{\mathrm{H}_{3} \mathrm{O}^{+}} \text {ratio }^{2}\end{array}$ & $\begin{array}{l}\text { Sensitivity }{ }^{3} \\
\text { ncps ppb }^{-1}\end{array}$ & $\begin{array}{r}\text { Detection } \\
\text { limit }^{4}, \text { ppt }\end{array}$ & $\begin{array}{l}\text { PTR-MS } \\
\text { type/calibration } \\
\text { method }^{5}\end{array}$ & Reference \\
\hline Acetic acid & $\sim 120$ & $N / R$ & $8 \pm 0.4$ & 820 & SS/indirect & De Gouw et al. (2003) \\
\hline \multirow[t]{9}{*}{$(m / z 61)$} & 132 & $N / R$ & $6.9-7$ & 160 & SS/PT & Haase et al. (2012) \\
\hline & & & $8.5-10.9$ & $320-60^{6}$ & HS/PT & \\
\hline & 116 & $\mathrm{~N} / \mathrm{R}$ & $14.3 \pm 0.8$ & & & \\
\hline & 132 & 0.01 & $11.60 \pm 0.16$ & 73 & $\mathrm{HS} / \mathrm{PT}$ & This study \\
\hline & 125 & 0.082 & $9.40 \pm 0.17$ & 118 & & \\
\hline & & 0.058 & $10.05 \pm 0.27$ & 102 & & \\
\hline & & 0.028 & $11.22 \pm 0.41$ & 78 & & \\
\hline & & 0.017 & $12.25 \pm 0.39$ & 69 & & \\
\hline & & 0.011 & $13.51 \pm 0.22$ & 64 & & \\
\hline \multirow[t]{7}{*}{ Formic acid } & $\sim 136$ & $<0.04$ & $5.7-7.3^{7}$ & & HS/DSI & Jardine et al. (2011) \\
\hline & 132 & 0.01 & $6.87 \pm 0.10$ & 206 & $\mathrm{HS} / \mathrm{PT}$ & This study \\
\hline & 125 & 0.082 & $5.69 \pm 0.12$ & 301 & & \\
\hline & & 0.058 & $6.20 \pm 0.19$ & 246 & & \\
\hline & & 0.028 & $7.35 \pm 0.23$ & 190 & & \\
\hline & & 0.017 & $7.90 \pm 0.30$ & 182 & & \\
\hline & & 0.011 & $8.98 \pm 0.19$ & 144 & & \\
\hline Glycolaldehyde $(m / z$ 61) & 125 & $0.013-0.090$ & $10-14.44$ & $85-77^{6}$ & $\mathrm{HS} / \mathrm{PT}$ & This study \\
\hline 2-propanol & 125 & $0.01-0.090$ & $0.038-0.047$ & $22400-23800$ & $\mathrm{HS} / \mathrm{PT}$ & This study \\
\hline Ethyl acetate (fragment at $m / z 61$ ) & 125 & $0.01-0.090$ & $10-11.6$ at $m / z 61$ & $85-96$ & $\mathrm{HS} / \mathrm{PT}$ & This study \\
\hline \multirow[t]{3}{*}{$(m / z 47)$} & $\sim 106$ & $\mathrm{~N} / \mathrm{R}$ & 3 & & SS/SGM & Warneke et al. (2003) \\
\hline & $\sim 136$ & $<0.04$ & $0.42-0.5^{7} ; 0.21-0.25^{8}$ & & HS/DSI & Jardine et al. (2011) \\
\hline & 125 & $0.010-0.095$ & $0.60-0.91$ & $2810-1390^{6}$ & HS/PT & This study \\
\hline
\end{tabular}

\subsection{Sensitivities}

In this section we examine the effects of humidity and $E / N$ on the PTR-MS response for AA, FA, and related species. Chemicals were introduced to the PTR-MS inlet system using the permeation system described above except for glycolaldehyde, which was introduced by flowing ultrapure air $(10 \mathrm{sccm})$ through $1 / 4^{\prime \prime}$ PFA tubing housing a small amount of crystalline glycolaldehyde dimer (Sigma Aldrich) on glass wool at temperatures of $26-35^{\circ} \mathrm{C}$. Table 1 compares measured sensitivities for the species of interest here with reported literature values, and lists the major product ions of $\mathrm{AA}, \mathrm{FA}$, and related species.

\subsubsection{Humidity dependence of PTR-MS sensitivity toward AA and FA}

To quantify the effect of humidity on the PTR-MS response for FA, AA, and their potential interferences, we carried out an ensemble of laboratory calibrations at varying humidity levels using the permeation system described above. To this end, room air was first passed through a $\mathrm{CaSO}_{4}$ bed to remove ambient moisture, then through a dew point generator (LICOR LI-610) and to the PTR-MS inlet where it was spiked with a given VOC. The resulting water vapor pressure in the sampled air stream varied between 0.60 and $3.50 \mathrm{kPa}$, equivalent to relative humidity (RH) values of $18-100 \%$ at $25^{\circ} \mathrm{C}$.

Figure 3 shows AA and FA calibration curves (normalized to $\left.I_{\mathrm{H}_{3} \mathrm{O}^{+}}\right)$as a function of $\mathrm{RH}$ at $E / N=125$ Townsend $\left(1 \mathrm{Td}=10^{-17} \mathrm{~V} \mathrm{~cm}^{2}\right)$. As we see in the figure, the PTR-MS response (ncps) varies linearly with the acid concentration (ppb), with the slope of the linear least squares fit yielding the normalized sensitivity $\left(\mathrm{ncps} \mathrm{ppb}^{-1}\right.$ ) at a given $\mathrm{RH}$ (Eq. 1). At $E / N=125 \mathrm{Td}$, the PTR-MS sensitivity decreases with increasing humidity for both $\mathrm{AA}$ and FA. Using the ratio of $\left(\mathrm{H}_{2} \mathrm{O}\right)-\mathrm{H}_{3} \mathrm{O}^{+}$to $\mathrm{H}_{3} \mathrm{O}^{+}\left(I_{\left(\mathrm{H}_{2} \mathrm{O}\right)-\mathrm{H}_{3} \mathrm{O}+}: I_{\mathrm{H}_{3} \mathrm{O}^{+}}\right)$as 


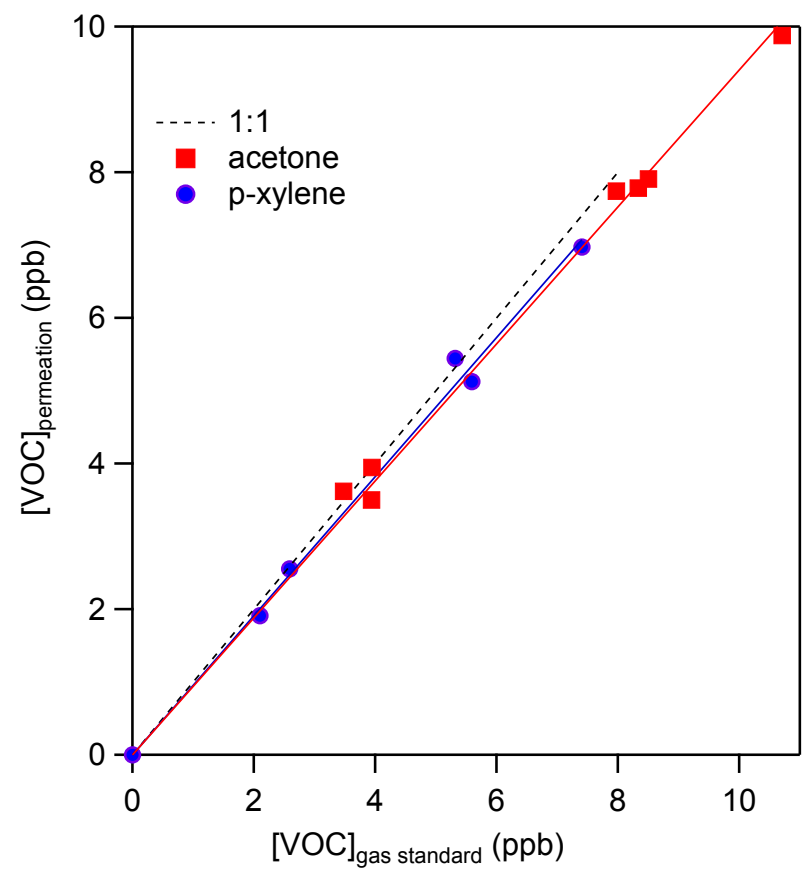

Figure 2. Validation of the permeation-based VOC calibration system based on known concentrations of $p$-xylene and acetone. In both cases, mixing ratios derived from a permeation-based calibration are compared to the actual values from a certified gas-phase standard. Good agreement (within 5\%) is found for both species.

a proxy for the sample humidity (de Gouw and Warneke, 2007), we find sensitivities for AA and FA that decrease from $(13.33 \pm 0.15)$ and $(8.81 \pm 0.12) \mathrm{ncpsppb}^{-1}$ at $I_{\left(\mathrm{H}_{2} \mathrm{O}\right)-\mathrm{H}_{3} \mathrm{O}+}: I_{\mathrm{H}_{3} \mathrm{O}^{+}}=0.011$ to $(9.45 \pm 0.14)$ and $(5.61 \pm 0.09)$ ncps ppb ${ }^{-1}$ at $I_{\left(\mathrm{H}_{2} \mathrm{O}\right)-\mathrm{H}_{3} \mathrm{O}+}: I_{\mathrm{H}_{3} \mathrm{O}^{+}}=0.082$ (Table 1). Quoted uncertainties represent the $\pm 2 \sigma$ precision of the fit. These sensitivities are within the range of the published values summarized in Table 1, though for most prior studies a lack of information about the sample RH prevents a fully quantitative comparison.

Figure 4 summarizes the humidity dependence of the PTR-MS response to carboxylic acids at $E / N=125 \mathrm{Td}$. Here, normalized sensitivity values are plotted against $I_{\left(\mathrm{H}_{2} \mathrm{O}\right)-\mathrm{H}_{3} \mathrm{O}+}: I_{\mathrm{H}_{3} \mathrm{O}^{+}}$, with each point representing an independent calibration obtained either in the laboratory or in the field (East St. Louis; see Sect. 3). The lines show biexponential fits to the laboratory data for predicting instrument sensitivity as a function of humidity in the field (in this case, at $E / N=125 \mathrm{Td}$ ), with shaded regions illustrating $\pm 15 \%$ of the predicted values. Due to small $(<10 \%)$ calibration offsets under laboratory versus field conditions, we first obtained the shape of the humidity dependence by normalizing the laboratory calibrations to the sensitivity values at $I_{\left(\mathrm{H}_{2} \mathrm{O}\right)-\mathrm{H}_{3} \mathrm{O}+}: I_{\mathrm{H}_{3} \mathrm{O}^{+}}=0.058$ and then applied the resulting shape factor to the field data. The ensuing humidity correction curves for FA and AA (shown by the green

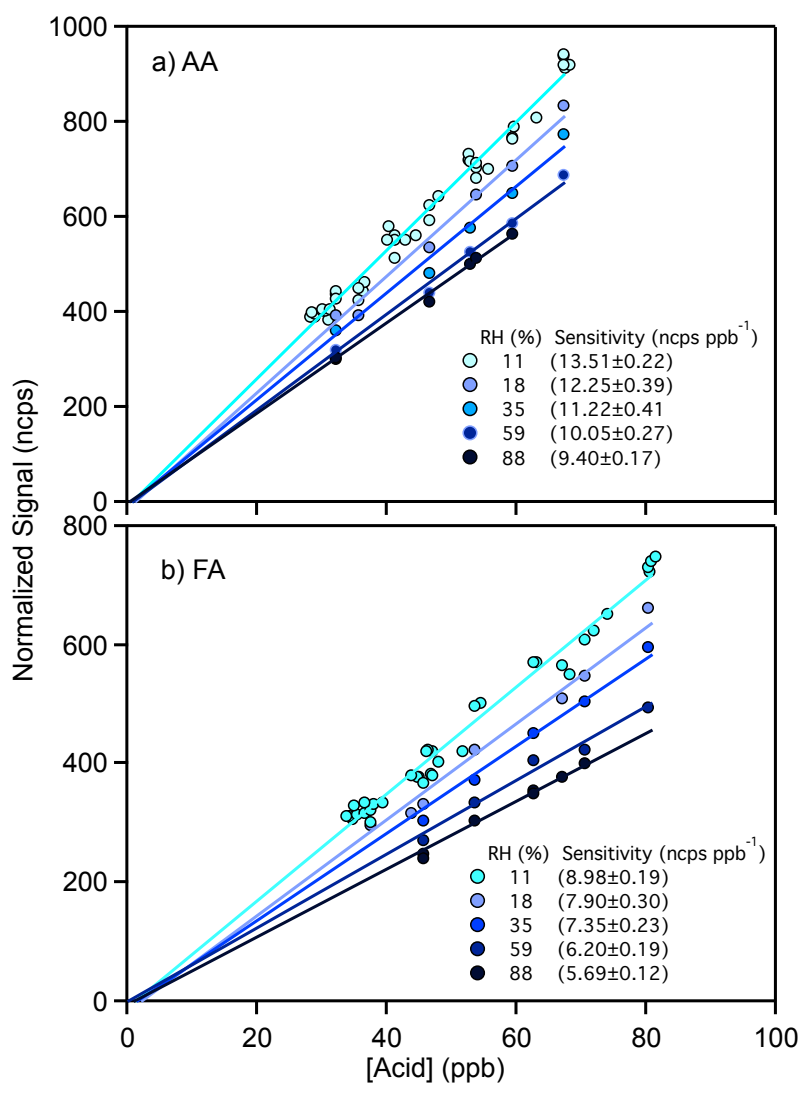

Figure 3. (a) AA and (b) FA calibration curves for varying humidity levels at $E / N=125 \mathrm{Td}$. Each line represents a linear least squares fit to the data at a given humidity. The normalized sensitivity is obtained as the slope in each case, and the corresponding relative humidity values are listed. Quoted uncertainties are $\pm 2 \sigma$ precision.

lines in Fig. 4) reveal a $\sim 40$ and $55 \%$ decrease in sensitivity, respectively, for RH changes between 18 and $100 \%$ $\left(I_{\left(\mathrm{H}_{2} \mathrm{O}\right)-\mathrm{H}_{3} \mathrm{O}+}: I_{\mathrm{H}_{3} \mathrm{O}^{+}}=0.01\right.$ and 0.13$)$ at $E / N=125 \mathrm{Td}$. As will be shown below, however, this behavior depends significantly on the collisional energy in the PTR-MS drift tube.

We also see in Fig. 4a an initial rapid decrease in PTR-MS sensitivity for AA as humidity increases, followed by an apparent plateau at high humidity values. However, the sensitivity for FA continues to decrease with humidity throughout the full range of $I_{\left(\mathrm{H}_{2} \mathrm{O}\right)-\mathrm{H}_{3} \mathrm{O}+}: I_{\mathrm{H}_{3} \mathrm{O}^{+}}$ratios (Fig. $4 \mathrm{~b}$ ). In addition, while the reported rate coefficients for the proton transfer reaction of $\mathrm{AA}$ and $\mathrm{FA}$ with $\mathrm{H}_{3} \mathrm{O}^{+}$are simi$\operatorname{lar}\left(3 \times 10^{-9} \mathrm{~cm}^{3} \mathrm{~s}^{-1}\right.$ and $2.7 \times 10^{-9} \mathrm{~cm}^{3} \mathrm{~s}^{-1}$, respectively; Lindinger et al., 1998), Figs. 3 and 4 reveal that the PTRMS sensitivity for AA is 1.5-1.7 times that for FA at $E / N=125 \mathrm{Td}$, depending on the humidity. This suggests the importance of other mechanisms affecting the sensitivity for these compounds, such as reactions with $\left(\mathrm{H}_{2} \mathrm{O}\right)-\mathrm{H}_{3} \mathrm{O}^{+}$ ions and fragmentation of the parent $\mathrm{CH}_{3} \mathrm{COOH}-\mathrm{H}^{+}$and $\mathrm{HCOOH}-\mathrm{H}^{+}$ions in the PTR-MS drift tube. In the following section we explore the major product ion distributions for 


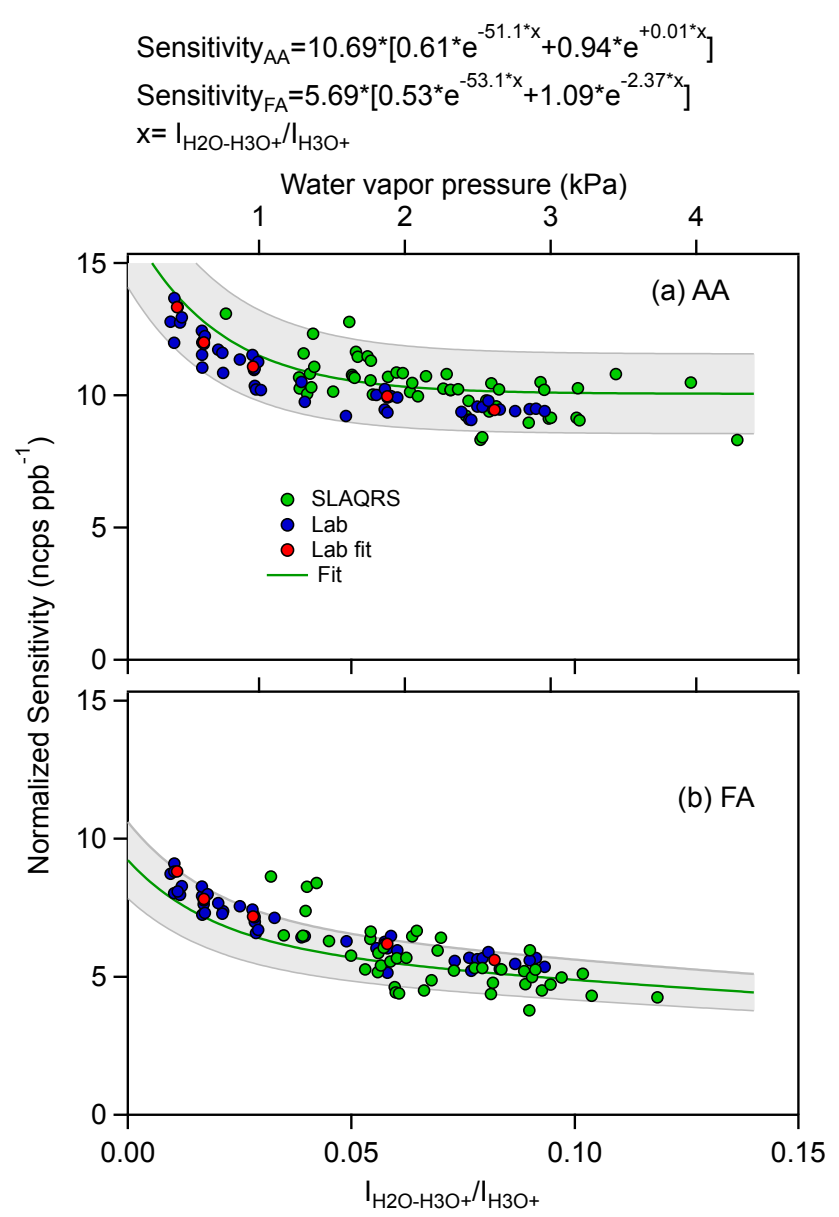

Figure 4. Humidity dependence of the PTR-MS response to (a) AA and (b) FA at $E / N=125 \mathrm{Td}$. Normalized sensitivity values obtained in the field (SLAQRS campaign in East St. Louis, USA) and in the laboratory are shown. A double exponential fit (green lines) was used to quantify and correct for the humidity dependence of the AA and FA sensitivities. Shaded areas represent $\pm 15 \%$ of the fit predictions. See text for details.

AA, FA, and related isobaric compounds (i.e., potential interferences) as a function of humidity and collisional energy in order to derive new insights into the reaction mechanisms and ion-molecule interactions governing their detection by PTR-MS.

\subsubsection{Combined effects of $E / N$ and humidity on PTR-MS response for AA, FA, and related species}

Figure 5 shows the distribution of major product ions derived from $\mathrm{H}_{3} \mathrm{O}^{+}$, AA, FA, glycolaldehyde $\left(\mathrm{HOCH}_{2} \mathrm{CHO}\right)$, ethyl acetate $\left(\mathrm{CH}_{3} \mathrm{C}(\mathrm{O}) \mathrm{OCH}_{2} \mathrm{CH}_{3}\right)$, 2propanol $\left(\mathrm{CH}_{3} \mathrm{CH}(\mathrm{OH}) \mathrm{CH}_{3}\right)$, ethanol $\left(\mathrm{CH}_{3} \mathrm{CH}_{2} \mathrm{OH}\right)$, and DME $\left(\mathrm{CH}_{3} \mathrm{OCH}_{3}\right)$ as a function of $E / N$ and humidity. Here, $E / N$ values were varied between 85 and $142 \mathrm{Td}$ by adjusting the drift tube voltage from 390 to $650 \mathrm{~V}$ and the drift tube pressure from 2.0 to 2.4 mbar. Organic product
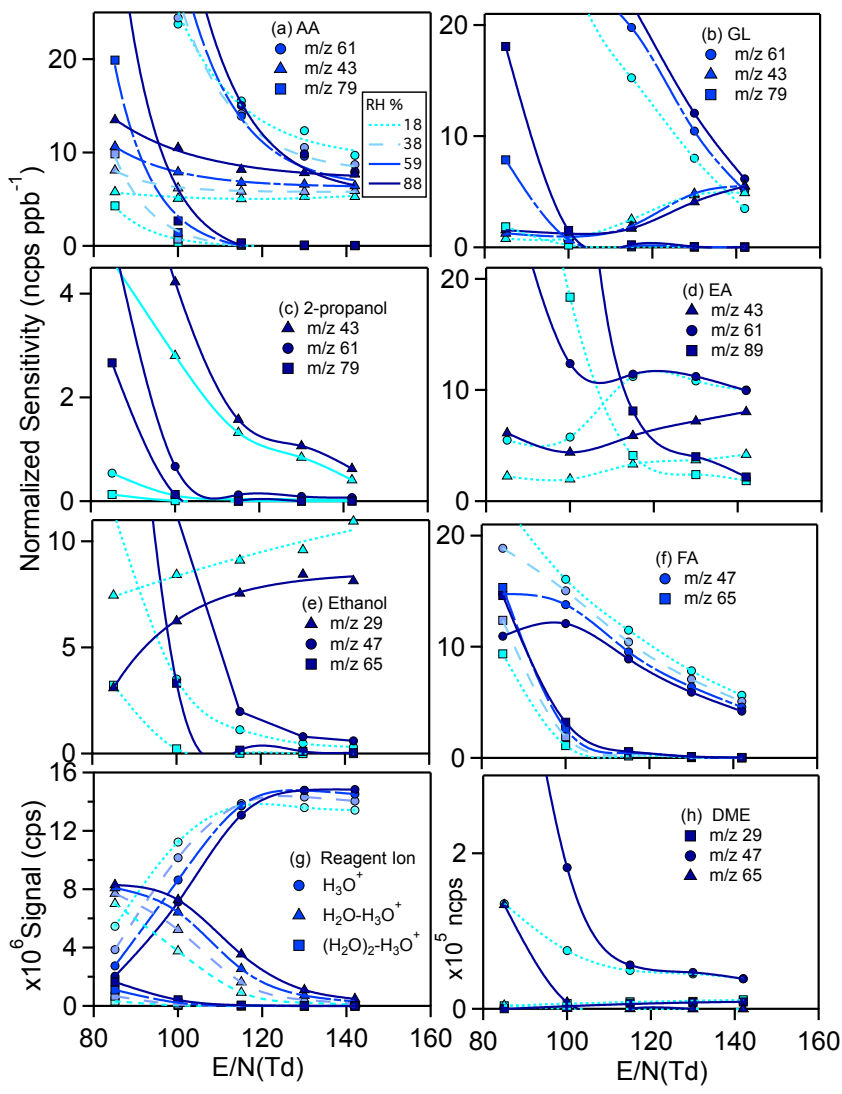

Figure 5. Distribution of major product ions originating from (a) AA, (b) glycolaldehyde (GL), (c) 2-propanol, (d) ethyl acetate (EA), (e) ethanol, (f) FA, (g) $\mathrm{H}_{3} \mathrm{O}^{+}$, and (h) dimethyl ether (DME) as a function of $E / N$ and humidity.

ion signals are normalized to the $\mathrm{H}_{3} \mathrm{O}^{+}$abundance and concentration and are given in units of ncps $\mathrm{ppb}^{-1}$. Figure 6 shows the corresponding relative yields of major product ions for each analyte (i.e., the ratio of the measured signal to the total signal from all major product ions).

As expected, we see in Fig. $5 \mathrm{~g}$ low abundances of the water cluster ions $\left(\mathrm{H}_{2} \mathrm{O}\right)-\mathrm{H}_{3} \mathrm{O}^{+}$and $\left(\mathrm{H}_{2} \mathrm{O}\right)_{2}-\mathrm{H}_{3} \mathrm{O}^{+}$at $E / N$ $>120 \mathrm{Td}$ due to high ion kinetic energy; under these conditions the primary $\mathrm{H}_{3} \mathrm{O}^{+}$ion is mainly in its unhydrated form. For example, at $E / N=130 \mathrm{Td}$ and $\sim 90 \%$ sample RH, the $\left(\mathrm{H}_{2} \mathrm{O}\right)-\mathrm{H}_{3} \mathrm{O}^{+}$signal accounts for only $\sim 7 \%$ of the total ion signal. Clustering of water becomes more efficient at lower $E / N$ and higher humidity (Fig. $5 \mathrm{~g}$ ): at $E / N=85 \mathrm{Td}$ and $\sim 90 \% \mathrm{RH}$, the $\left(\mathrm{H}_{2} \mathrm{O}\right)-\mathrm{H}_{3} \mathrm{O}^{+}$and $\mathrm{H}_{3} \mathrm{O}^{+}$ions account for $>70$ and $14 \%$ of the total ion signal, respectively.

A number of competing processes can affect the PTR-MS sensitivity toward a particular compound, including the proton transfer reaction forming $\mathrm{R}-\mathrm{H}^{+}$, fragmentation of $\mathrm{R}-\mathrm{H}^{+}$ via elimination of $\mathrm{H}_{2} \mathrm{O}$ or other functional groups, interaction of $\mathrm{R}-\mathrm{H}^{+}$ions with $\mathrm{H}_{2} \mathrm{O}$ molecules leading to a fragment ion or a stabilized molecular ion, and ligand switching reactions with $\left(\mathrm{H}_{2} \mathrm{O}\right)-\mathrm{H}_{3} \mathrm{O}^{+}$that can result in formation of $\mathrm{R}-\mathrm{H}^{+}$ 
Table 2. Summary of proposed mechanisms taking place in the PTR-MS drift tube accounting for the distribution of product ions originating from AA, FA, and related species.

\begin{tabular}{|c|c|c|c|c|c|}
\hline Neutral & Proton & Reactions & & & \\
\hline $\begin{array}{l}\text { Acetic } \\
\text { acid }\end{array}$ & 187.3 & $\begin{array}{l}\mathrm{H}_{3} \mathrm{O}^{+}+\mathrm{AA} \\
\left\{\mathrm{AA}-\mathrm{H}^{+}\right\}^{*} \\
\mathrm{AA}-\mathrm{H}^{+}+\mathrm{H}_{2} \mathrm{O} \\
\left(\mathrm{H}_{2} \mathrm{O}\right)-\mathrm{H}_{3} \mathrm{O}^{+}+\mathrm{AA}\end{array}$ & $\begin{array}{l}\rightarrow\left\{\mathrm{AA}-\mathrm{H}^{+}\right\}^{*}+\mathrm{H}_{2} \mathrm{O} \\
\rightarrow \mathrm{AA}-\mathrm{H}^{+} \\
\rightarrow \mathrm{CH}_{3} \mathrm{CO}^{+}+\mathrm{H}_{2} \mathrm{O} \\
\rightarrow \rightarrow \mathrm{CH}_{3} \mathrm{CO}^{+}+2 \mathrm{H}_{2} \mathrm{O} \\
\rightarrow \mathrm{AA}^{-} \mathrm{H}_{3} \mathrm{O}^{+} \\
\rightarrow+\mathrm{AA}^{+} \mathrm{H}^{+}+2 \mathrm{H}_{2} \mathrm{O} \\
\rightarrow \mathrm{AA}^{-} \mathrm{H}_{3} \mathrm{O}^{+}+\mathrm{H}_{2} \mathrm{O}\end{array}$ & $\begin{array}{l}(m / z 61) \\
(m / z 43) \\
(m / z 43) \\
(m / z 79) \\
(m / z 61) \\
(m / z 79)\end{array}$ & $\begin{array}{l}\text { (R1) } \\
\text { (R1a) } \\
\text { (R1b) } \\
\text { (R2a) } \\
\text { (R2b) } \\
\text { (R3a) } \\
\text { (R3b) }\end{array}$ \\
\hline $\begin{array}{l}\text { Formic } \\
\text { acid }\end{array}$ & 177.3 & $\begin{array}{l}\mathrm{H}_{3} \mathrm{O}^{+}+\mathrm{FA} \\
\left\{\mathrm{FA}-\mathrm{H}^{+}\right\}^{*} \\
\text { FA- } \mathrm{H}^{+}+\mathrm{H}_{2} \mathrm{O} \\
\left(\mathrm{H}_{2} \mathrm{O}\right)-\mathrm{H}_{3} \mathrm{O}^{+}+\mathrm{FA}\end{array}$ & $\begin{array}{l}\rightarrow\left\{\mathrm{FA}^{-\mathrm{H}^{+}}\right\}^{*}+\mathrm{H}_{2} \mathrm{O} \\
\rightarrow \text { FA- } \mathrm{H}^{+} \\
\rightarrow \text { neutral FA or product } \\
\rightarrow \text { neutral FA/product }+\mathrm{H}_{3} \mathrm{O}^{+} \\
\rightarrow \text { FA- } \mathrm{H}_{3} \mathrm{O}^{+} \\
\rightarrow \mathrm{FA}^{+} \mathrm{H}_{3} \mathrm{O}^{+}+\mathrm{H}_{2} \mathrm{O}\end{array}$ & $\begin{array}{l}(m / z 65) \\
(m / z 65)\end{array}$ & $\begin{array}{r}\text { (R4) } \\
\text { (R4a) } \\
\text { (R4b) } \\
\text { (R5a) } \\
\text { (R5b) } \\
\text { (R6) }\end{array}$ \\
\hline $\begin{array}{l}\text { Glycolal- } \\
\text { dehyde }\end{array}$ & $N / R^{2}$ & $\begin{array}{l}\mathrm{H}_{3} \mathrm{O}^{+}+\mathrm{GL} \\
\left\{\mathrm{GL}-\mathrm{H}^{+}\right\}^{*} \\
\mathrm{GL}^{*} \mathrm{H}^{+}+\mathrm{H}_{2} \mathrm{O} \\
\left(\mathrm{H}_{2} \mathrm{O}\right)-\mathrm{H}_{3} \mathrm{O}^{+}+\mathrm{GL}\end{array}$ & 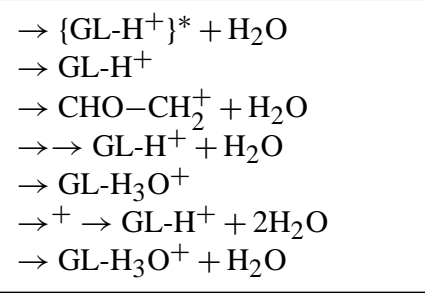 & $\begin{array}{l}(m / z 61) \\
(m / z 43) \\
(m / z 61) \\
(m / z 79) \\
(m / z 61) \\
(m / z 79) \\
\end{array}$ & $\begin{array}{l}\text { (R7) } \\
\text { (R7a) } \\
\text { (R7b) } \\
\text { (R8a) } \\
\text { (R8b) } \\
\text { (R9a) } \\
\text { (R9b) }\end{array}$ \\
\hline 2-propanol & 189.4 & $\begin{array}{l}\mathrm{H}_{3} \mathrm{O}^{+}+\mathrm{R} \\
\left\{\mathrm{R}-\mathrm{H}^{+}\right\}^{*} \\
\mathrm{R}-\mathrm{H}^{+}+\mathrm{H}_{2} \mathrm{O} \\
\left(\mathrm{H}_{2} \mathrm{O}\right)-\mathrm{H}_{3} \mathrm{O}^{+}+\mathrm{R}\end{array}$ & $\begin{array}{l}\rightarrow\left\{{\mathrm{R}-\mathrm{H}^{+}}^{*}+\mathrm{H}_{2} \mathrm{O}\right. \\
\rightarrow \mathrm{R}^{+} \mathrm{H}^{+} \\
\rightarrow\left(\mathrm{CH}_{3} \mathrm{CHCH}_{3}\right)^{+}+\mathrm{H}_{2} \mathrm{O} \\
\rightarrow \rightarrow \mathrm{R}^{+} \mathrm{H}^{+}+\mathrm{H}_{2} \mathrm{O} \\
\rightarrow \mathrm{R}^{-} \mathrm{H}_{3} \mathrm{O}^{+} \\
\rightarrow+\rightarrow \mathrm{R}^{-} \mathrm{H}^{+}+2 \mathrm{H}_{2} \mathrm{O} \\
\rightarrow \mathrm{R}^{-} \mathrm{H}_{3} \mathrm{O}^{+}+\mathrm{H}_{2} \mathrm{O}\end{array}$ & $\begin{array}{l}(m / z 61) \\
(m / z 43) \\
(m / z 61) \\
(m / z 79) \\
(m / z 61) \\
(m / z 79)\end{array}$ & $\begin{array}{l}\text { (R10) } \\
\text { (R10a) } \\
\text { (R10b) } \\
\text { (R11a) } \\
\text { (R11b) } \\
\text { (R12a) } \\
\text { (R12b) }\end{array}$ \\
\hline Ethanol & 188.3 & $\begin{array}{l}\mathrm{H}_{3} \mathrm{O}^{+}+\mathrm{R} \\
\left\{\mathrm{R}-\mathrm{H}^{+}\right\}^{*} \\
\mathrm{R}-\mathrm{H}^{+}+\mathrm{H}_{2} \mathrm{O} \\
\left(\mathrm{H}_{2} \mathrm{O}\right)-\mathrm{H}_{3} \mathrm{O}^{+}+\mathrm{R}\end{array}$ & $\begin{array}{l}\rightarrow\left\{\mathrm{R}^{-\mathrm{H}^{+}}\right\}^{*}+\mathrm{H}_{2} \mathrm{O} \\
\rightarrow{\mathrm{R}-\mathrm{H}^{+}} \\
\rightarrow\left(\mathrm{CH}_{3} \mathrm{CH}_{2}\right)^{+}+\mathrm{H}_{2} \mathrm{O} \\
\rightarrow \rightarrow \mathrm{R}^{+} \mathrm{H}^{+}+\mathrm{H}_{2} \mathrm{O} \\
\rightarrow \mathrm{R}-\mathrm{H}_{3} \mathrm{O}^{+} \\
\rightarrow+\mathrm{R}^{+} \mathrm{H}^{+}+2 \mathrm{H}_{2} \mathrm{O} \\
\rightarrow \mathrm{R}^{-} \mathrm{H}_{3} \mathrm{O}^{+}+\mathrm{H}_{2} \mathrm{O}\end{array}$ & $\begin{array}{l}(m / z 47) \\
(m / z 29) \\
(m / z 47) \\
(m / z 65) \\
(m / z 47) \\
(m / z 65)\end{array}$ & $\begin{array}{l}\text { (R13) } \\
\text { (R13a) } \\
\text { (R13b) } \\
\text { (R14a) } \\
\text { (R14b) } \\
\text { (R15a) } \\
\text { (R15b) }\end{array}$ \\
\hline $\begin{array}{l}\text { Dimethyl- } \\
\text { ether }\end{array}$ & 189.2 & $\begin{array}{l}\mathrm{H}_{3} \mathrm{O}^{+}+\mathrm{DME}^{+} \\
\left\{\mathrm{DME}-\mathrm{H}^{+}\right\}^{*} \\
\text { DME- } \mathrm{H}^{+}+\mathrm{H}_{2} \mathrm{O} \\
\left(\mathrm{H}_{2} \mathrm{O}\right)-\mathrm{H}_{3} \mathrm{O}^{+}+\mathrm{DME}\end{array}$ & 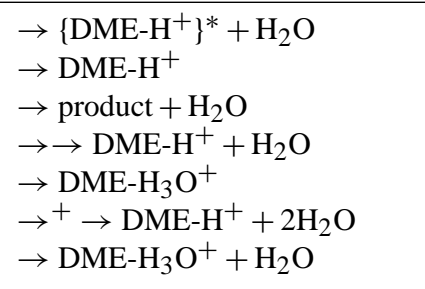 & $\begin{array}{l}(m / z 47) \\
(m / z 29) \\
(m / z 47) \\
(m / z 65) \\
(m / z 47) \\
(m / z 65)\end{array}$ & $\begin{array}{l}\text { (R16) } \\
\text { (R16a) } \\
\text { (R16b) } \\
\text { (R17a) } \\
\text { (R17b) } \\
\text { (R18a) } \\
\text { (R18b) }\end{array}$ \\
\hline
\end{tabular}


Table 2. Continued.

\begin{tabular}{|c|c|c|c|c|c|}
\hline $\begin{array}{l}\text { Neutral } \\
\text { molecules }\end{array}$ & $\begin{array}{l}\text { Proton } \\
\text { affinity }^{1} \text {, } \\
\text { kcal mol }^{-1}\end{array}$ & Reactions & & & \\
\hline $\begin{array}{l}\text { Ethyl } \\
\text { acetate }\end{array}$ & 199.6 & $\begin{array}{l}\mathrm{H}_{3} \mathrm{O}^{+}+\mathrm{R} \\
\left\{\mathrm{R}^{-} \mathrm{H}^{+}\right\}^{*} \\
\text { AA- } \mathrm{H}^{+} \\
\mathrm{R}-\mathrm{H}^{+}+\mathrm{H}_{2} \mathrm{O} \\
\mathrm{AA}-\mathrm{H}^{+}+\mathrm{H}_{2} \mathrm{O} \\
\left(\mathrm{H}_{2} \mathrm{O}\right)-\mathrm{H}_{3} \mathrm{O}^{+}+\mathrm{R}\end{array}$ & $\begin{array}{l}\rightarrow\left\{\mathrm{R}_{-} \mathrm{H}^{+}\right\}^{*}+\mathrm{H}_{2} \mathrm{O} \\
\rightarrow \mathrm{R}-\mathrm{H}^{+} \\
\rightarrow \rightarrow \mathrm{AA}-\mathrm{H}^{+}+\text {neutral } \\
\rightarrow \mathrm{CH}_{3} \mathrm{CO}^{+}+\mathrm{H}_{2} \mathrm{O} \\
\rightarrow{\mathrm{R}-\mathrm{H}^{+}+\mathrm{H}_{2} \mathrm{O}} \rightarrow \rightarrow \mathrm{AA}^{-} \mathrm{H}^{+}+\text {neutral }+\mathrm{H}_{2} \mathrm{O} \\
\rightarrow \rightarrow \mathrm{CH}_{3} \mathrm{CO}^{+}+2 \mathrm{H}_{2} \mathrm{O} \\
\rightarrow \mathrm{AA}^{-} \mathrm{H}_{3} \mathrm{O}^{+} \\
\rightarrow+\rightarrow \mathrm{R}-\mathrm{H}^{+}+\mathrm{H}_{2} \mathrm{O} \\
\rightarrow \rightarrow \text { AA- } \mathrm{H}^{+}+\text {neutral }+\mathrm{H}_{2} \mathrm{O} \\
\rightarrow^{+} \rightarrow \mathrm{R}-\mathrm{H}_{3} \mathrm{O}^{+}+\mathrm{H}_{2} \mathrm{O}\end{array}$ & $\begin{array}{l}(m / z 89) \\
(m / z 61) \\
(m / z 43) \\
(m / z 89) \\
(m / z 61) \\
(m / z 43) \\
(m / z 79) \\
(m / z 89) \\
(m / z 61) \\
(m / z 107)\end{array}$ & $\begin{array}{r}\text { (R19) } \\
(\mathrm{R} 19 a) \\
(\mathrm{R} 19 \mathrm{~b}) \\
(\mathrm{R} 1 \mathrm{~b}) \\
(\mathrm{R} 20 \mathrm{a}) \\
(\mathrm{R} 20 \mathrm{~b}) \\
(\mathrm{R} 2 \mathrm{a}) \\
\text { (R2b) } \\
\text { (R21a) } \\
\text { (R21b) } \\
\text { (R21c) }\end{array}$ \\
\hline $\begin{array}{l}\text { Peroxyacetic } \\
\text { acid }\end{array}$ & $\mathrm{N} / \mathrm{R}^{2}$ & $\begin{array}{l}\mathrm{H}_{3} \mathrm{O}^{+}+\mathrm{R} \\
\mathrm{AA}-\mathrm{H}^{+} \\
\mathrm{R}-\mathrm{H}^{+}+\mathrm{H}_{2} \mathrm{O} \\
\mathrm{AA}-\mathrm{H}^{+}+\mathrm{H}_{2} \mathrm{O} \\
\left(\mathrm{H}_{2} \mathrm{O}\right)-\mathrm{H}_{3} \mathrm{O}^{+}+\mathrm{R}\end{array}$ & 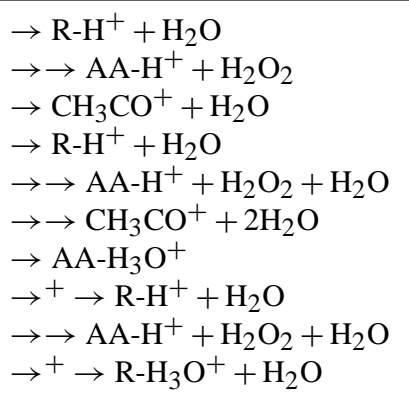 & $\begin{array}{l}(m / z 77) \\
(m / z 61) \\
(m / z 43) \\
(m / z 77) \\
(m / z 61) \\
(m / z 43) \\
(m / z 79) \\
(m / z 77) \\
(m / z 61) \\
(m / z 95)\end{array}$ & $\begin{array}{r}(\mathrm{R} 22 \mathrm{a}) \\
(\mathrm{R} 22 \mathrm{~b}) \\
(\mathrm{R} 1 \mathrm{~b}) \\
(\mathrm{R} 23 \mathrm{a}) \\
(\mathrm{R} 23 \mathrm{~b}) \\
(\mathrm{R} 2 \mathrm{a}) \\
(\mathrm{R} 2 \mathrm{~b}) \\
(\mathrm{R} 24 \mathrm{a}) \\
(\mathrm{R} 24 \mathrm{~b}) \\
\text { (R24c) }\end{array}$ \\
\hline
\end{tabular}

1 (Hunter and Lias, 1998). ${ }^{2} \mathrm{~N} / \mathrm{R}$ : not reported in the literature.

and $\mathrm{R}-\mathrm{H}_{3} \mathrm{O}^{+}$. We see from Figs. 5 and 6 that the relative importance of these processes depends on the mean collisional energy (thus $E / N$ ), the abundance of water molecules, and the functionality of the species at hand. Proper accounting for the effect of humidity on sensitivity needs to account for all of these competing processes (Table 2).

For all of the organic species in Figs. 5 and 6, we see a decrease in the abundance of molecular ions and their hydrates (and correspondingly more fragment ions) with increasing $E / N$. The higher sensitivity towards the molecular ions at low $E / N$ is partly due to the increased reaction time in the drift tube and partly to the reduced collisional energy and hence lower degree of fragmentation under these conditions. Likewise, clustering reactions become more efficient at low $E / N$, leading to higher abundances of the corresponding hydrates. Beyond these common features, Figs. 5 and 6 reveal significantly different product ion distributions and humidity dependencies between AA, FA, and the related species examined here. We explore these below in terms of the implied mechanisms governing the ion chemistry in each case. Table 2 lists proposed mechanisms along with the proton affinity for each compound.

\section{AA}

The major product ions originating from $\mathrm{AA}$ are (i) the acylium ion $\left(\mathrm{CH}_{3} \mathrm{CO}^{+}\right)$at $\mathrm{m} / z, 43$ resulting from the loss of $\mathrm{H}_{2} \mathrm{O}$ upon protonation of AA, (ii) the AA- $\mathrm{H}^{+}$ion at $m / z$ 61 , and (iii) the hydrated $\mathrm{AA}$ ion $\left(\mathrm{AA}-\mathrm{H}_{3} \mathrm{O}^{+}\right.$) at $m / z 79$ (Table 2). Although proton transfer between $\mathrm{H}_{3} \mathrm{O}^{+}$and $\mathrm{AA}$ is only slightly exothermic, and the dissociation reaction (1b) for $\mathrm{AA}-\mathrm{H}^{+}$is endothermic (Spanel et al., 2003), we observe very efficient fragmentation of $\mathrm{AA}-\mathrm{H}^{+}$: up to $\sim 50 \%$ at $E / N=142 \mathrm{Td}$ when the ion kinetic energy can be as high as $\sim 10 \mathrm{kcal} \mathrm{mol}^{-1}$.

At elevated $E / N(>\sim 120 \mathrm{Td})$, we also see more efficient fragmentation of AA- $\mathrm{H}^{+}$with increasing humidity, leading to reduced PTR-MS sensitivity toward AA (i.e., the molecular ion) at high $E / N$ and high RH. For example, the branching ratio for fragmentation of AA- $\mathrm{H}^{+}$increases from $\sim 30$ to $50 \%$ as the water vapor pressure changes from 0.61 to $3 \mathrm{kPa}$ at $E / N=142 \mathrm{Td}$ (Figs. 5a and 6a), which in turn leads to a $\sim 30 \%$ reduction in PTR-MS sensitivity to AA. This is consistent with the findings of Feilberg et al. (2010), who reported more extensive fragmentation of protonated acetic acid at high RH.

At low $E / N$, fragmentation reactions become less efficient and hydrated hydronium ions are more abundant. As a result, ligand switching reactions of $\mathrm{AA}$ with $\left(\mathrm{H}_{2} \mathrm{O}\right)-\mathrm{H}_{3} \mathrm{O}^{+}$ 
(reactions $3 \mathrm{a}$ and $3 \mathrm{~b}$ in Table 2) become important, and we observe increases in both $\mathrm{AA}-\mathrm{H}^{+}$and $\mathrm{AA}-\mathrm{H}_{3} \mathrm{O}^{+}$with rising RH. The net effect at low $E / N$ is an increase in PTR-MS sensitivity towards AA (at $m / z 61$ ) with increasing humidity (Fig. 5a).

At intermediate $E / N$ values, these two competing processes (fragmentation of molecular ions and ligand switching reactions) roughly cancel, so that the net sensitivity towards AA at $m / z \quad 61$ appears independent of humidity as observed by Haase et al. (2012) and Warneke et al. (2001). This crossover point for $m / z 61$ is seen in Fig. 5a at $\sim 115 \mathrm{Td}$. In a similar way, under our standard operating conditions $(E / N=125 \mathrm{Td})$, sensitivity towards AA at $m / z$ 61 becomes humidity-independent for $I_{\left(\mathrm{H}_{2} \mathrm{O}\right)-\mathrm{H}_{3} \mathrm{O}+}: I_{\mathrm{H}_{3} \mathrm{O}^{+}}$ $>\sim 0.5$ (Fig. 4a). We attribute this to the same two competing processes: dissociation of $\mathrm{AA}-\mathrm{H}^{+}$via interaction with water molecules and ligand switching reactions between AA and $\left(\mathrm{H}_{2} \mathrm{O}\right)-\mathrm{H}_{3} \mathrm{O}^{+}$leading to formation of $\mathrm{AA}-\mathrm{H}^{+}$.

\section{FA}

FA product ions were detected at $m / z 47$ and 65 (Fig. 5f). If fragmentation of $\mathrm{FA}-\mathrm{H}^{+}$proceeded via $\mathrm{H}_{2} \mathrm{O}$ elimination, we would expect to see a fragment ion at $m / z$ 29. None was detected, ruling out the $\mathrm{H}_{2} \mathrm{O}$ elimination pathway. Fragmentation could proceed via reverse reaction (back to $\mathrm{FA}+\mathrm{H}_{3} \mathrm{O}^{+}$) or by dissociation to a neutral product or a product ion at a different mass. Because no fragmentation product was detected in this case, Fig. 6 does not show a product yield distribution for FA.

Figure 5 shows that increases in $E / N$ and $\mathrm{RH}$ both lead to reduced PTR-MS sensitivity toward FA at $m / z$ 47. Unlike AA, where the humidity dependence switches sign, the effect of humidity on FA sensitivity is negative throughout the full range of $E / N$. Hence we propose a mechanism whereby fragmentation of $\mathrm{FA}-\mathrm{H}^{+}$is enhanced by the presence of water molecules at high $E / N$, leading to a negative humidity dependence under such conditions (Fig. 4b; Table 2). However, unlike AA, the FA product ion signal at $m / z 47$ drops with increasing humidity at low $E / N$ as well. In parallel, we see in Fig. 5f a strong increase in the hydrated formic acid signal at $m / z 65$ as humidity rises at low $E / N$. For instance, at $E / N=85 \mathrm{Td}$ and $\mathrm{RH}=\sim 100 \%, \mathrm{FA}_{-} \mathrm{H}_{3} \mathrm{O}^{+}$at $m / z 65$ accounts for more than $60 \%$ of the total FA ion signal. This implies that the ligand switching reaction of FA with $\left(\mathrm{H}_{2} \mathrm{O}\right)$ $\mathrm{H}_{3} \mathrm{O}^{+}$to form FA-H ${ }^{+}$is less important than the clustering reaction that forms $\mathrm{FA}-\mathrm{H}_{3} \mathrm{O}^{+}$. Together with water-driven fragmentation at high $E / N$, this accounts for the continuous decrease in PTR-MS sensitivity for FA with rising humidity (Fig. 4b).

\section{Glycolaldehyde, 2-propanol, dimethyl ether, and ethanol}

PTR-MS sensitivities towards these four species exhibit similar trends with $E / N$ and humidity, although the magnitude

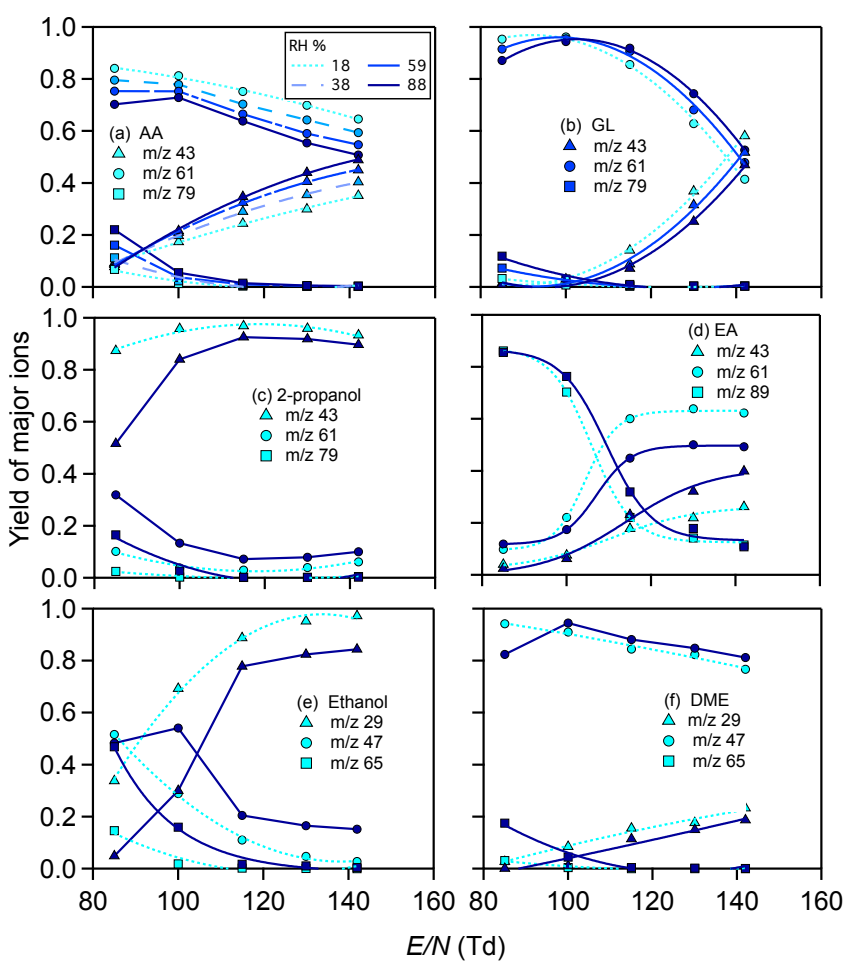

Figure 6. Yields of major product ions originating from (a) AA, (b) glycolaldehyde, (c) 2-propanol, (d) ethyl acetate, (e) ethanol, and (f) DME as a function of $E / N$ and humidity. Those of FA are not shown here because no fragmentation product was detected by PTR-MS.

of the effect varies. Product ions derived from glycolaldehyde and 2-propanol were detected at $m / z$ 43, 61, and 79 (Figs. 5b, c and 6b, c) while those from ethanol and DME were detected at $m / z, 29,47$, and 65 (Figs. 5e, h and 6e, f). All exhibit $\mathrm{H}_{2} \mathrm{O}$ elimination pathways, with the corresponding fragment ions detected at $\mathrm{m} / \mathrm{z} 43$ and $\mathrm{m} / \mathrm{z} 29$.

As expected, fragmentation of the molecular $\mathrm{R}-\mathrm{H}^{+}$ions is most efficient at high $E / N$ values (Fig. 6). Under such conditions (e.g., $E / N>\sim 115 \mathrm{Td}$ ), we see that $>80 \%$ of the $\mathrm{R}-\mathrm{H}^{+}$ions derived from propanol and ethanol undergo dissociation, which gives rise to the observed low sensitivity towards these alcohols.

In contrast, fragmentation yields for glycolaldehyde and DME are lower ( $<\sim 50$ and $20 \%$, respectively; Fig. 6), leading to higher PTR-MS sensitivity towards these compounds. Here, addition of water appears to inhibit dissociation of R$\mathrm{H}^{+}$based on the reduced branching ratio for fragmentation with increasing humidity. Hence the PTR-MS sensitivity towards glycolaldehyde and DME is positively correlated with humidity at high $E / N$, opposite in behavior to AA and FA. This positive humidity dependence is shown in Fig. 7, where the sensitivities for (a) glycolaldehyde and (b) ethanol at $E / N=125 \mathrm{Td}$ are plotted against the $I_{\left(\mathrm{H}_{2} \mathrm{O}\right)-\mathrm{H}_{3} \mathrm{O}+}: I_{\mathrm{H}_{3} \mathrm{O}^{+}}$ 


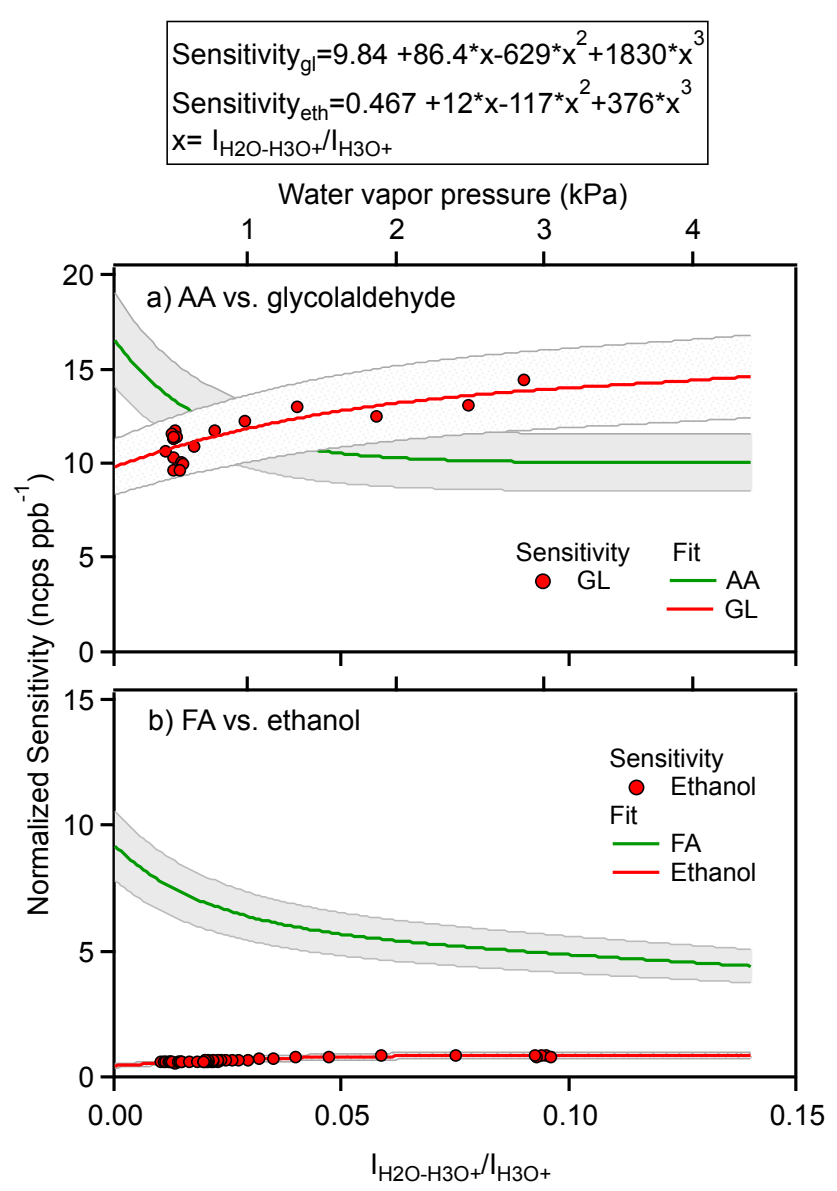

Figure 7. Humidity dependence of the PTR-MS response to (a) glycolaldehyde and AA and (b) ethanol and FA at $E / N=125 \mathrm{Td}$. The polynomial fits shown in the figure were used to quantify and correct for the humidity dependence of the glycolaldehyde and ethanol sensitivities. The shaded areas represent $\pm 15 \%$ of the fitted values.

ratio and compared to the corresponding values for $\mathrm{AA}$ and FA.

We also see in Figs. 5 and 6 that reducing the collisional energy in the drift tube (i.e., $E / N$ ) significantly affects the PTR-MS sensitivity towards 2-propanol and ethanol: in the case of 2-propanol, the branching ratio for fragmentation decreases from $\sim 90$ to $50 \%$ as $E / N$ decreases from 142 to $85 \mathrm{Td}$. At low $E / N$, sensitivity towards the 2-propanol and ethanol molecular ions and their respective hydrates is positively correlated with humidity (as is the case for AA), indicative of ligand switching reactions and clustering.

\section{Ethyl acetate $\left(\mathrm{CH}_{3} \mathrm{C}(\mathrm{O}) \mathrm{OCH}_{2} \mathrm{CH}_{3}\right)$}

The $\mathrm{R}-\mathrm{H}^{+}$molecular ion for ethyl acetate was detected at $\mathrm{m} / z 89$ and its fragmentation products at $m / z 43$ and $\mathrm{m} / z 61$ (Figs. $5 \mathrm{~d}$ and $6 \mathrm{~d}$ ). At low $E / N$, the yield for the molecular ion at $m / z 89$ is high ( $>90 \%$ at $E / N=85 \mathrm{Td}$ ). However, due to efficient fragmentation with increasing collisional en- ergy in the drift tube, we see in Fig. 6 that for $E / N>100 \mathrm{Td}$ the $m / z 61$ fragment ion can account for $>50 \%$ of the total ion signal, whereas the yield for the molecular ion at $m / z 89$ is low (e.g., $\sim 10 \%$ at $E / N=142 \mathrm{Td}$ ). Under such conditions, PTR-MS sensitivity towards the ethyl acetate molecular ion is low, but sensitivity towards the $m / z 61$ fragment ion is comparable to that for the AA molecular ion (also at $m / z$ 61) (Table 2). At high $E / N$, the effect of humidity on the signals at $m / z 61$ and $m / z 43$ appears to be consistent for both ethyl acetate and AA, with the yield of $m / z 61$ decreasing with humidity while that of $m / z 43$ increases with humidity (Fig. 5). Hence we speculate that the $m / z 61$ fragment ion is AA- $\mathrm{H}^{+}$and that further fragmentation of this product yields the $m / z 43$ fragment ion.

\section{Peroxyacetic acid $\left(\mathrm{CH}_{3} \mathrm{C}(\mathrm{O}) \mathrm{OOH}\right)$}

Because commercial PAA contains a large amount of AA ( $\sim 45 \%)$, we were neither able to isolate the effects of humidity and $E / N$ on the product ions derived from PAA nor determine the corresponding sensitivity. However, we observed that the reaction of PAA proceeds mostly via fragmentation of PAA- $\mathrm{H}^{+}$to yield the $\mathrm{AA}-\mathrm{H}^{+}$ion detected at $m / z 61$ (See Table 2). This observation is consistent with the reports of Spanel et al. (2003). Hence, similar to the results for ethyl acetate, the PAA fragment ion at $m / z, 61$ will have the same sensitivity as AA- $\mathrm{H}^{+}$, with an inverse dependence on humidity at high $E / N$.

An important finding for the above compounds is that the impact of humidity on PTR-MS sensitivity towards a given VOC and $m / z$ ratio can depend strongly on the collisional energy in the PTR-MS drift tube (i.e., $E / N$ ). In the case of AA, the effect actually switches sign for low versus high $E / N$ values. In such cases, the use of a single humidity correction factor such as $X_{\mathrm{R}}$ (de Gouw and Warneke, 2007) will only be appropriate for the particular instrumental configuration and $E / N$ used in its derivation.

\subsection{Implications for ambient measurements of FA and AA by PTR-MS}

As described above, humidity affects the PTR-MS response to AA, FA, and their potential interferences to varying degrees, and in some cases with opposing sign (e.g., Fig. 7). Consequently, the relative importance of the various interferences will depend on ambient humidity. As a compromise between the fragmentation of the molecular ions and contributions from ligand switching reactions of AA, FA, and their mass analogues, we recommend an intermediate $E / N$ value of $125 \mathrm{Td}$ for monitoring AA and FA. In this section we discuss the potential role of interferences when measuring FA, AA, and benzene by PTR-MS at $m / z$ 47, 61, and 79, respectively. Table 1 lists the calibration factors for these species. 
$m / z 47$

Figure $7 \mathrm{~b}$ compares the normalized PTR-MS sensitivities with respect to FA and ethanol as a function of humidity at $E / N=125 \mathrm{Td}$. The sensitivity for FA is 20 times greater than that for ethanol when humidity is low. However, this is reduced to a $\sim 5$ times difference at the high end of the humidity range due to the opposing water-sensitivity relationships for FA and ethanol. In general, we expect ethanol to be only a minor interference for FA measurements by quadrupole PTR-MS except in situations where ethanol is present in significantly higher abundance than FA. The two species can potentially be resolved independently using highresolution time-of-flight PTR-MS (Blake et al., 2009; A. Jordan et al., 2009).

DME can also potentially interfere with quadrupole PTRMS measurements of FA at $m / z$ 47. We did not quantify the instrumental sensitivity to DME (which would have involved exposure to a high temperature in the presence of oxygen) due to its flammability. However, we expect the PTRMS sensitivity towards DME to be high based on the low fragmentation yield for DME-H ${ }^{+}$(Fig. 5h). In most circumstances, the atmospheric abundance of DME is likely to be very low (Good et al., 1998); however, if present, DME has the potential to interfere with FA measurements at $m / z 47$.

\section{$m / z 61$}

The AA molecular ion at $m / z 61$ is isobaric with product ions from glycolaldehyde, ethyl acetate, and PAA, and nominally isobaric with the molecular ion from propanols. The sensitivity towards 2-propanol is very low $(<1 \%$ that of AA at $E / N=125 \mathrm{Td}$ ), so that propanols will not typically be an important interference for AA measurements by PTR-MS. However, we find that the PTR-MS sensitivities towards glycolaldehyde, ethyl acetate, and PAA at $m / z 61$ are comparable to that for AA (Table 1). Therefore, separating the various contributions from these species is a prerequisite for accurate measurements of AA by PTR-MS.

Glycolaldehyde, which is isomeric with AA, is thought to be produced during the photochemical oxidation of isoprene (Dibble, 2004; Paulot et al., 2009) and is removed by $\mathrm{OH}$ chemistry and photolysis (Atkinson et al., 2006). Clair et al. (2014) recently measured a mean glycolaldehyde concentration of 986 pptv at a forested site in the Sierra Nevada foothills of California. Figure 7a compares the PTR-MS calibration factors for glycolaldehyde and AA as a function of humidity at $E / N=125 \mathrm{Td}$. As can be seen, sensitivity to the two compounds at $m / z 61$ is comparable at an RH of 20$40 \%$, but the PTR-MS becomes preferentially sensitive to glycolaldehyde as the humidity increases.

When present, ethyl acetate and PAA will interfere with AA measurements by PTR-MS. Ethyl acetate is used in coatings, as a process solvent, and in a variety of adhesives and cosmetics. Plumes with ethyl acetate mixing ratios as high as $183 \mathrm{ppb}$ have been observed during the night in Mexico City (Fortner et al., 2009). PAA is produced from the reaction of $\mathrm{CH}_{3} \mathrm{C}(\mathrm{O}) \mathrm{O}_{2}$ radicals with $\mathrm{HO}_{2}$, a pathway that can be important when $\mathrm{NO}_{x}$ concentrations are low (Dillon and Crowley, 2008).

$m / z 79$

The hydrated product ions of AA, glycolaldehyde, and propanols occur at $m / z 79$, which is also widely used in PTR-MS studies to quantify benzene concentrations. However, in all cases the formation yield of $m / z, 79$ is $<1 \%$ at $E / N=125 \mathrm{Td}$, leading to sensitivity values (e.g., $<0.1$ ncps per ppb of AA) that are much lower than those of benzene (e.g., $\sim 12 \mathrm{ncpsppb}^{-1}$ ). The interference to benzene measurements from these compounds will thus be negligible in most atmospheric environments for $E / N>100 \mathrm{Td}$. However, this interference can be significant when operating at low $E / N$. For example, when $E / N=88 \mathrm{Td}$ the yield of $m / z$ 79 is $>20 \%$ at $88 \%$ RH (Fig. 6), which could become important when benzene concentrations are low.

\subsection{Development of an acid trap to separate isobaric interferences for AA and FA}

As shown above, glycolaldehyde, propanols, ethyl acetate, PAA (at $m / z$ 61), and ethanol and DME (at $m / z$ 47) can all potentially interfere with ambient measurement of AA and FA by PTR-MS. To address this issue, we built a trap that takes advantage of the adsorptive nature of AA and FA to separate these compounds from their interfering species at $\mathrm{m} / z 61$ and 47 . This acid trap consists of a $10 \mathrm{~cm}$ length of temperature-controlled $1 / 4^{\prime \prime}$ O.D. stainless steel tubing containing $\mathrm{KOH}$-treated CarboBlack B packing material (Mesh 60/80; Restek Corp.). KOH-treated CarboBlack B strongly adsorbs carboxylic acids such as AA and FA, while having very little adsorption affinity for alcohols or other interfering VOCs. Thus, by periodically diverting the incoming air sample through the acid trap, the contribution from AA and FA interferences to the signals at $m / z 61$ and 47 can be determined, and the actual AA and FA abundance quantified by difference.

The trap was kept at ambient temperature and installed immediately upstream of the PTR-MS, held in an upright position with the gas flow entering at the bottom and moving up through the loosely packed adsorbents in the trap. In this way, when the inlet flow $(\sim 35 \mathrm{sccm})$ is diverted through the trap, the adsorbent materials move upward with the flow and increase the exposure time. A tightly packed trap was found to restrict the flow and led to the loss of compounds such as glycolaldehyde. When not in use, the acid trap is purged constantly with $\sim 40 \mathrm{sccm}$ of ultrapure air. The main advantage of this design (e.g., in contrast to a chromatographic column) is its fast response, which prevents any significant delay in 


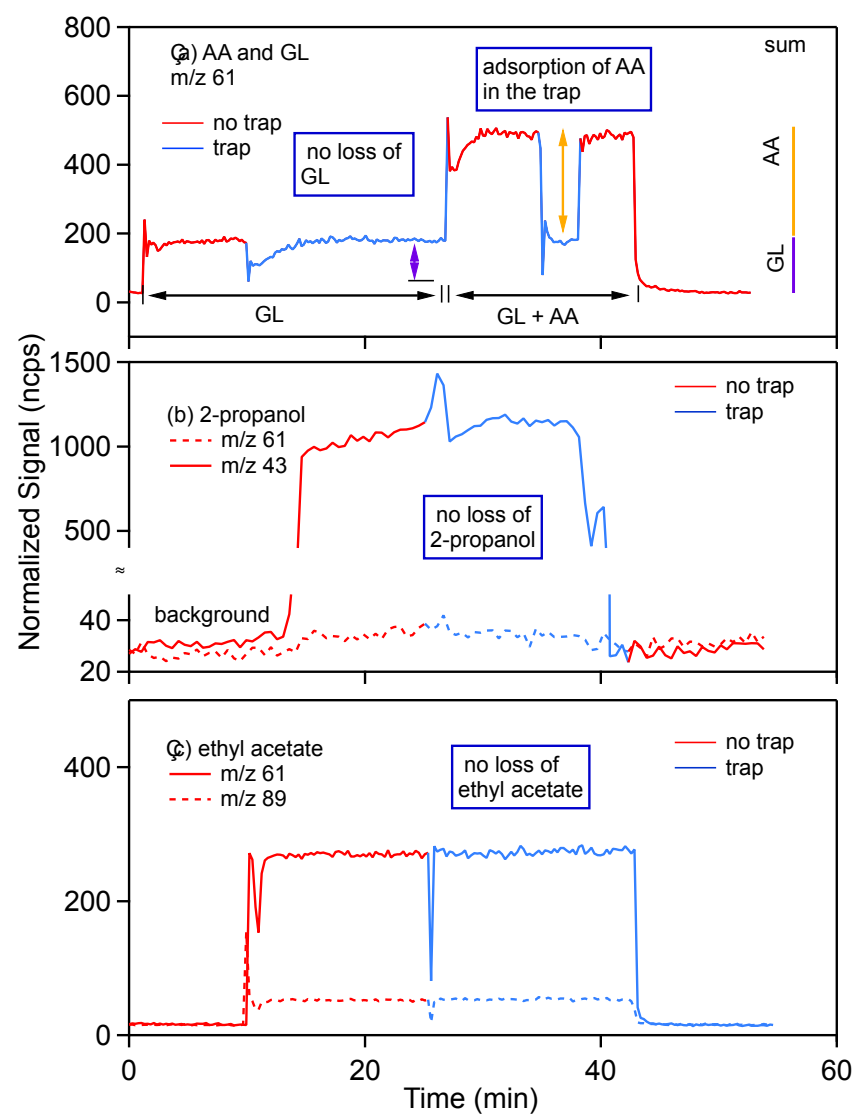

Figure 8. Separation of isobaric species detected at $m / z, 61$ in the laboratory using the acid trap. Shown are (a) AA and glycolaldehyde (GL), (b) 2-propanol, and (c) ethyl acetate. "No trap" indicates periods when the acid trap was bypassed. AA is quantitatively retained by the trap, whereas glycolaldehyde, ethyl acetate, and 2propanol are unaffected.

measurement time; the typical equilibration time when ambient air is sent through the acid trap is $\sim 3 \mathrm{~min}$.

Figures 8 and 9 demonstrate the acid trap performance for species detected at $m / z 61$ and $m / z$ 47. "Trap" (in blue) and "no trap" (red) measurements indicate periods when the sample flow was diverted through the acid trap and when it was introduced directly to the PTR-MS, respectively. We see in Fig. 8 that the $m / z 61$ ion signal is unaltered between the "no trap" and "trap" periods for glycolaldehyde, ethyl acetate, and 2-propanol. In each case, the signal quickly recovers to its previous level when the flow is diverted through the acid trap, indicating that these species are not removed by the trap. The "no trap" and "trap" measurements of a gas flow containing both AA and glycolaldehyde (Fig. 8a) show a decrease in the measured ion signal due to adsorption of AA by the trap. This decrease is equivalent to the observed increase in ion signal when the same amount of AA is added directly to the PTR-MS (Fig. 8a), demonstrating that the acid trap removes $>99 \%$ of the AA in the sampled air flow.

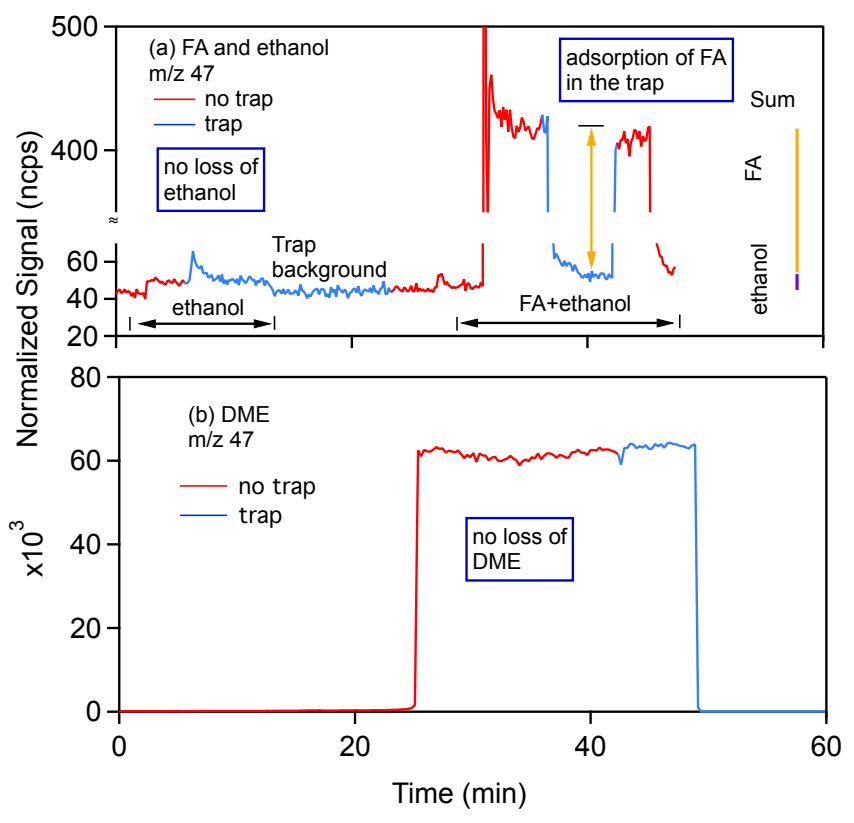

Figure 9. Separation of isobaric species detected at $\mathrm{m} / \mathrm{z} 47$ in the laboratory using the acid trap. Shown are (a) FA and ethanol and (b) DME. Formic acid is quantitatively retained in the trap, while DME and ethanol are unaffected.

In a similar way, we see in Fig. 9 that ethanol and DME are unaffected by the acid trap, while FA is quantitatively retained and removed from the gas flow. This acid trap design is thus effective at removing the isobaric interferences for $\mathrm{AA}$ and FA that are expected to be relevant in the ambient atmosphere. The exception is PAA, which we find is partially retained $(\sim 40 \%)$ by the acid trap.

\section{Deployment and performance in the field}

The PTR-MS instrument, along with the associated acid trap, inlet, and calibration system described above, was deployed to the St. Louis-Midwest Supersite core monitoring station located in East St. Louis, IL $\left(38.6122^{\circ} \mathrm{N}, 90.16028^{\circ} \mathrm{W}\right.$, $184 \mathrm{~m}$ elevation), as part of the SLAQRS (St. Louis Air Quality Regional Study) campaign from 2 August to 30 September 2013. A detailed description of the site is provided elsewhere (Lee et al., 2006b; Wang et al., 2011). We pulled a $10000 \mathrm{sccm}$ ambient flow from the top of the trailer $(5 \mathrm{~m}$ above ground) through $\sim 20 \mathrm{ft}$ of heated $1 / 2^{\prime \prime}$ O.D. PFA tubing. Approximately $1000 \mathrm{sccm}$ of this flow was diverted to the PTR-MS inlet system. The PTR-MS drift tube pressure and voltage were maintained at $2.3 \mathrm{mbar}$ and $600 \mathrm{~V}$, resulting in an $E / N$ of $126 \mathrm{Td}$ with an $\mathrm{H}_{2} \mathrm{O}$ flow to the ion source of $6.5 \mathrm{sccm}$. The abundance of $\mathrm{H}_{3} \mathrm{O}^{+}$ions was $(1.2-2) \times 10^{9}$ cps and interference from $\mathrm{O}_{2}^{+}$was minimal, amounting to less than $1 \%$ of the $\mathrm{H}_{3} \mathrm{O}^{+}$signal. A suite of $24 \mathrm{VOCs}$ was monitored during SLAQRS with dwell times ranging from 5 


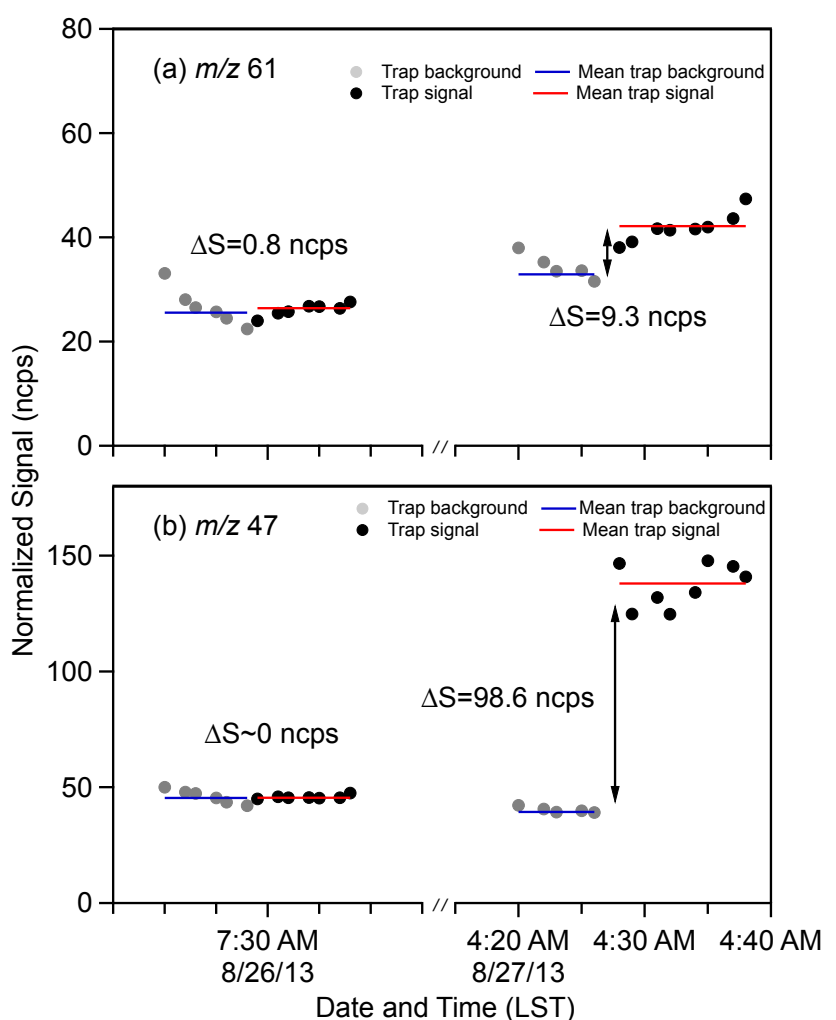

Figure 10. Example application of the acid trap in the field (SLAQRS campaign in East St. Louis, USA) for (a) $\mathrm{m} / z$ 61 and (b) $m / z$ 47. The left-hand section illustrates a time period when the acid trap measurements are indistinguishable from the trap background ( $\Delta S \sim 0$ ), indicating no detectable presence of non-acid interferences. The right-hand section illustrates a time period when there were detectable non-acid interferences at both $m / z$ values $(\Delta S>0)$.

to $10 \mathrm{~s}$. Dwell times for $m / z 61$ and $m / z 47$ were each $5 \mathrm{~s}$, and the overall measurement resolution was $1.6 \mathrm{~min}$.

\subsection{Trap performance}

The permeation-based VOC calibration apparatus and acid trap system were both automated. PTR-MS background measurements and the FA and AA calibrations were performed every $7 \mathrm{~h}$ in the field. Other VOCs were calibrated daily by dynamic dilution of ppm-level gas-phase standards as described in earlier papers (Hu et al., 2011, 2013). Acid trap measurements were performed every $2 \mathrm{~h}$ between calibrations. Each time, the trap background was monitored for $10 \mathrm{~min}$ by sending catalytically generated zero air through the acid trap and then to the PTR-MS. The corresponding ambient air measurement (via the acid trap) followed immediately and was likewise performed for $10 \mathrm{~min}$. The trap was conditioned for $2 \mathrm{~h}$ at $195^{\circ} \mathrm{C}$ every $2-3$ days and subsequently allowed to cool before use.

Figure 10 shows example acid trap measurements for $\mathrm{m} / \mathrm{z}$ 61 and $m / z 47$ obtained during SLAQRS. The figure com-

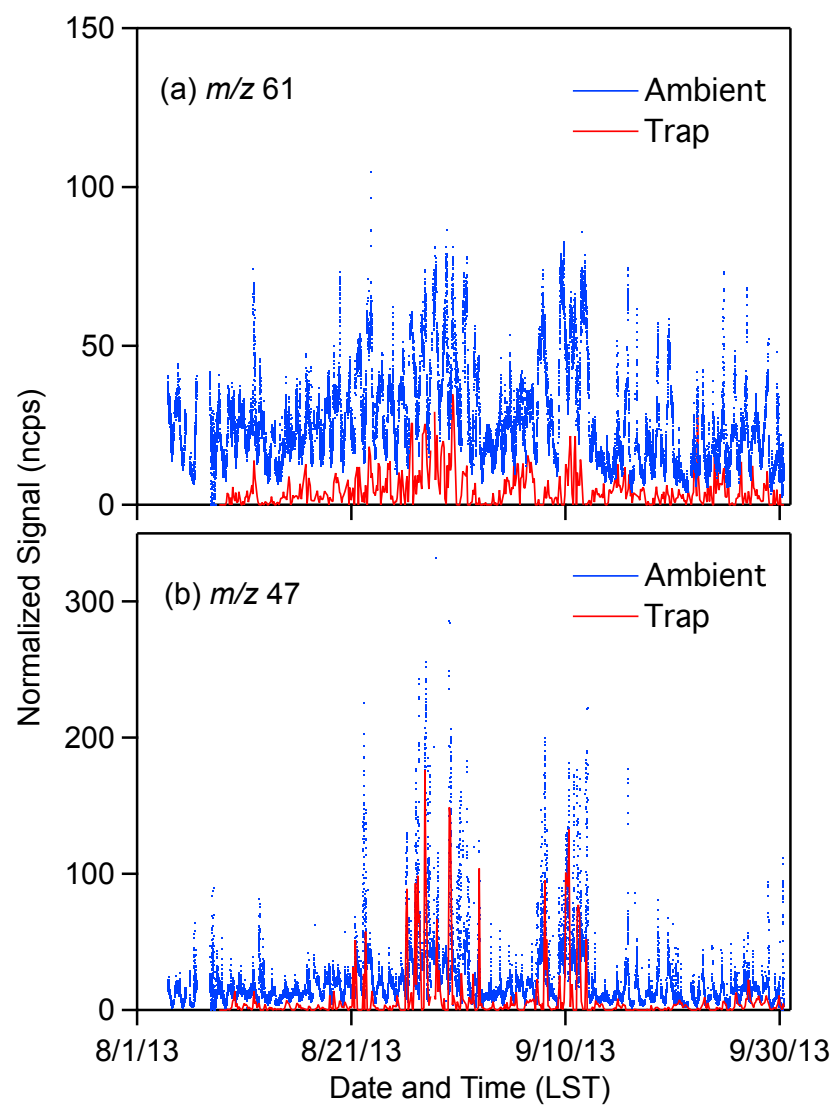

Figure 11. Ambient measurements of (a) $m / z 61$ and (b) $m / z 47$ during the SLAQRS campaign in East St. Louis, USA. Also shown are the acid trap measurements at the same $m / z$ values, corresponding to the sum of non-acid isobaric interferences.

pares ambient air sampled via the acid trap (in black) with the acid trap background (in gray) for two time periods. The first example (7:30 a.m. LST on 26 August 13) shows an instance where the trap backgrounds and the ambient trap measurements are statistically indistinguishable at both masses $(\Delta S \sim 0)$, indicating a negligible contribution from non-acid interferences in this case. The second example illustrates a period when there was a significant increase above the trap background $(\Delta S>0)$ for both $m / z 61$ and $m / z 47$, indicating the presence of isobaric interferences for the two species at this time.

Figure 11 shows the results of acid trap measurements $(\Delta S$ values) along with the unadjusted ambient measurements for (a) $m / z 61$ and (b) $m / z 47$ during the SLAQRS field deployment. We see that the ambient (i.e., AA plus interferences) and trap (i.e., interferences only) measurements of $m / z 61$ are well correlated $\left(R^{2}=0.81\right)$. The $m / z 61$ ion signal obtained from the trap measurements is usually small (18\% on average of the total signal at $m / z$ 61) but nonetheless detectable most of the time. The highest trap signal of $\sim 35$ ncps was observed on 27 and 28 August 2013, at which time it accounted for $\sim 40 \%$ of the total $\mathrm{m} / \mathrm{z} 61$ ion signal. 


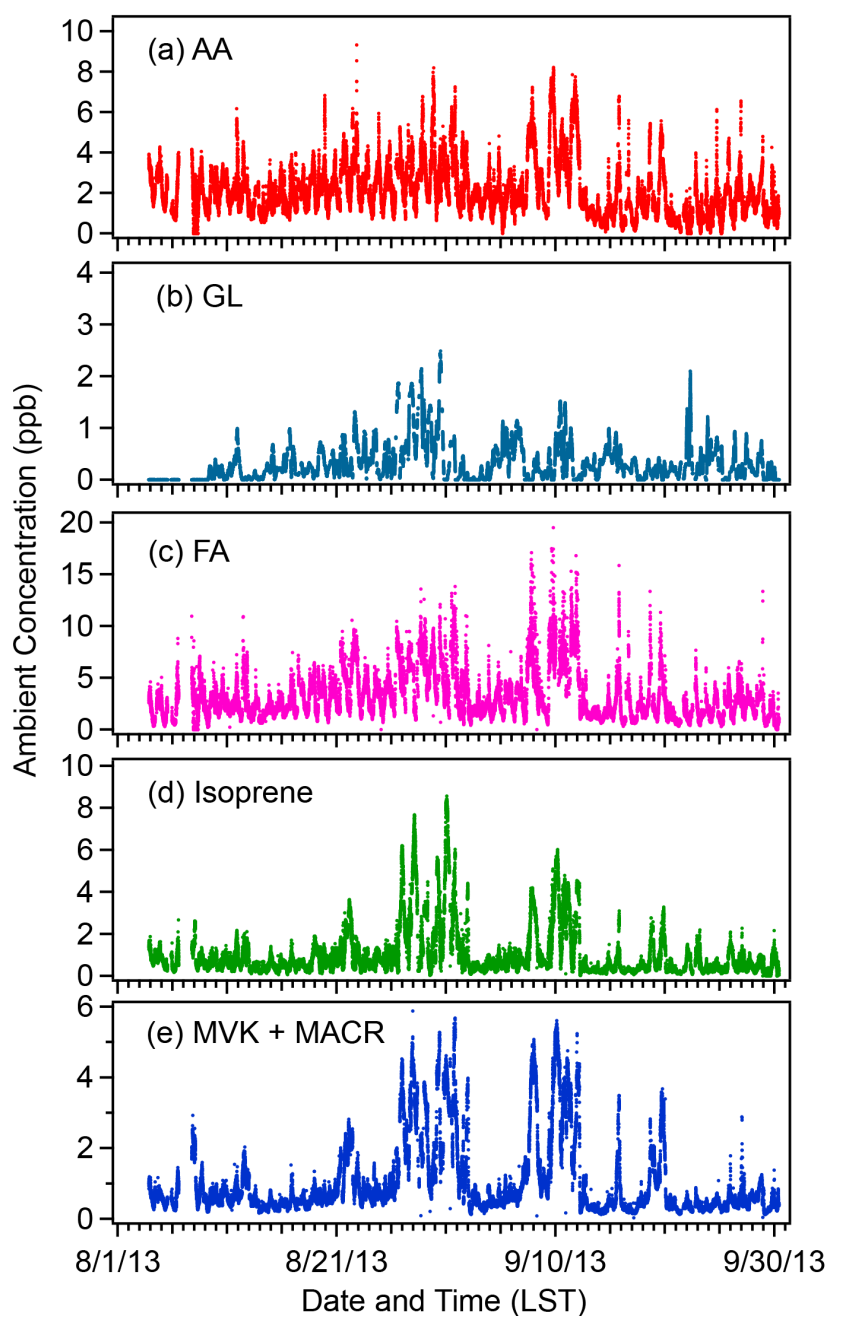

Figure 12. Time series of ambient (a) AA, (b) glycolaldehyde (GL), (c) FA, (d) isoprene, and (e) MVK+MACR mixing ratios measured by PTR-MS in East St. Louis, USA, during the SLAQRS measurement campaign. See text for details.

This time period featured southwesterly winds and high levels of isoprene and its oxidation products transported from the nearby Ozark Plateau. The interference is thus likely to be primarily glycolaldehyde, although PAA produced in the low-NO, high-VOC environment upwind may also be contributing.

The acid trap signal at $m / z 47$ was below our detection limit much of the time, except during certain nights. At these times, both the ambient (FA + interferences) and trap (interferences only) $m / z \quad 47$ measurements showed very large spikes (Fig. 11b), indicating a large, episodic contribution from species other than FA. These elevated trap measurements at $m / z 47$ apparently reflect pollution plumes containing large amounts of ethanol or DME. These plumes were very sporadic, lasting only 5-15 min, and were associated with a precise wind direction $\left(240^{\circ}\right.$, southwest of the field site), both of which are consistent with a strong direct emis- sion of ethanol or DME at night from a nearby industrial source. This appears to be a somewhat unusual case, and given the low PTR-MS sensitivity towards ethanol (Fig. 7) and the low expected ambient abundance of DME (Good et al., 1998), it is likely that such interferences at $m / z 47$ are minor in most (even urban) atmospheres. However, it does bear mentioning that a similar $m / z 47$ interference due to DME was detected using a proton-transfer ion trap-mass spectrometer in a narrow industrial plume near Houston, TX, during TexaQS 2006 (Veres et al., 2008).

\subsection{Time series of measured compounds}

Figure 12 shows temporal profiles of glycolaldehyde, AA, and FA measured by PTR-MS as part of SLAQRS in East St. Louis, IL, during summer 2013. The mixing ratios of these species were determined from the PTR-MS signals based on the observed humidity dependence of the corresponding calibration factors (Figs. 4 and 7). Also shown in Fig. 12 are the observed mixing ratios of isoprene and sum of its first-generation oxidation products methyl vinyl ketone and methacrolein (MVK+MACR).

The $m / z 61$ signal obtained from the acid trap measurements ranged between 0.04 and $0.84 \mathrm{ppb}$ (10-90th percentiles), with the highest values occurring on days when isoprene and MVK+MACR enhancements (up to 8 and $5 \mathrm{ppb}$; Fig. 12) were also observed. Based on this temporal variability, we have assumed here that the acid trap measurements at $m / z 61$ correspond solely to glycolaldehyde. However, it is possible that ethyl acetate and PAA are also contributing to some degree. In any case, the acid trap $m / z 61$ time series generally varied quite smoothly in time, thus enabling interpolation of the signal between acid trap measurements and estimation of AA mixing ratios by difference. The resulting AA mixing ratios are shown in Fig. 12. Concentrations of AA ranged between 0.78 and $3.93 \mathrm{ppb}$ (10-90th percentiles) and were highest during periods of high isoprene and MVK+MACR. AA showed a strong diurnal profile with a maximum occurring in early afternoon.

Unlike the glycolaldehyde signal at $m / z$ 61, the FA interference at $m / z \quad 47$ was episodic, associated with sporadic ethanol or DME pollution plumes (typically lasting 5-15 $\mathrm{min}$ ) as discussed earlier. Temporal interpolation was thus not a suitable means of quantifying this interference between trap measurements. However, these episodes were clearly distinguishable based on their anomalously high $m / z \quad 47: m / z 61$ ratios. Normally, the signals at $m / z 47$ and 61 were well correlated, giving an $[\mathrm{FA}] /[\mathrm{AA}]$ ratio of $(1.42 \pm 0.01)$ outside of the ethanol/DME plumes, compared to an implied ratio of $5.79 \pm 0.20$ within the plumes (uncertainties here represent $2 \sigma$ precision of the fit). In Fig. 12, we have therefore removed all $\mathrm{m} / \mathrm{z} 47$ data points with $\mathrm{m} / \mathrm{z}$ $47: m / z 61$ ratios $>3$ to eliminate the time periods impacted by these plumes and arrive at an estimate of the ambient FA abundance. An alternative approach would be to filter the 
data by wind direction. The resulting FA mixing ratios typically varied between 1.1 and $6.8 \mathrm{ppb}$ (10-90th percentiles), and as with AA and glycolaldehyde they were highest during periods of elevated isoprene and MVK+MACR. A detailed analysis of the above observations in terms of the constraints they can provide on sources and sinks of FA, AA, and related species will be presented in an upcoming publication.

\section{Summary}

We carried out an in-depth study of the processes governing the detection and quantification of formic acid, acetic acid, and a suite of related species by proton-transfer-reaction mass spectrometry. Instrumental sensitivity towards AA at $m / z 61$ decreases with humidity when the collisional energy in the PTR-MS drift tube is high $(E / N>125 \mathrm{Td})$ due to fragmentation of $\mathrm{AA}-\mathrm{H}^{+}$by water. At low $E / N$, the sensitivity increases with humidity because of the proton-transfer reaction between $\left(\mathrm{H}_{2} \mathrm{O}\right)-\mathrm{H}_{3} \mathrm{O}^{+}$and AA. At intermediate $E / N$ ( $\sim 115 \mathrm{Td}$ ) these processes offset each other and the overall sensitivity can become nearly humidity-independent.

Potential interferences for AA measurements at $m / z 61$ include glycolaldehyde (isomeric with AA), peroxyacetic acid and ethyl acetate (which give rise to $\mathrm{AA}-\mathrm{H}+$ detected at $m / z 61$ ), and propanols (nominally isobaric with AA). We find that the sensitivity towards propanols is extremely low ( $<1 \%$ that for AA under typical operating conditions), so that these will not represent a significant interference under most circumstances. However, the PTR-MS sensitivities towards glycolaldehyde, ethyl acetate, and PAA at $m / z 61$ are comparable to AA; contributions from these species need to be accounted for when interpreting $m / z 61$ observations in the ambient atmosphere. Furthermore, the relative influence from these different species will vary with RH. For example, while the PTR-MS sensitivities towards AA and the $m / z$ 61 product ion from ethyl acetate decrease with humidity at $E / N=125 \mathrm{Td}$, that for glycolaldehyde increases with humidity.

Unlike AA, the PTR-MS sensitivity towards FA decreases with humidity throughout the full range of $E / N$. We attribute this behavior to water-driven fragmentation of $\mathrm{FA}-\mathrm{H}^{+}$ at high $E / N$ and to formation of the hydrated $\mathrm{FA}-\left(\mathrm{H}_{3} \mathrm{O}^{+}\right)$ ion at low $E / N$. Potential (nominal) interferences for FA at $m / z 47$ include ethanol and DME. The PTR-MS sensitivity towards ethanol is low (5-20 times lower than for FA at $E / N=125 \mathrm{Td}$ ), whereas for DME it appears to be similar to or higher than that of FA. The sensitivities for both ethanol and DME increase with humidity, so that (when present) their influence will be highest at high $\mathrm{RH}$.

While AA, glycolaldehyde, and propanols all give rise to hydrated product ions at $m / z 79$ (also used for benzene measurements by PTR-MS), the formation yield is low at intermediate and high $E / N$ values (e.g., $<1 \%$ at $E / N=125 \mathrm{Td}$ ). The resulting interference for benzene mea- surements will thus only become relevant for low $E / N$ when benzene concentrations are relatively low.

We described here an acid trap that enables the online separation of FA and AA at $m / z 47$ and 61 from the compounds discussed previously, and demonstrated its performance. The trap quantitatively removed FA and AA from the sampled air stream without affecting the other oxygenated VOCs we tested at $m / z 47$ and 61. An exception is PAA, which is partially retained on the trap. With that caveat, the FA and AA abundance can then be quantified by difference.

Finally, we presented and briefly discussed PTR-MS measurements of AA, FA, and glycolaldehyde in an urban site impacted by strong biogenic VOC emissions (SLAQRS campaign during summer 2013). Observed concentrations of AA, FA, and glycolaldehyde typically varied between 0.78 and $3.93,1.1$ and 6.8 , and 0.04 and 0.84 ppb (10-90th percentiles), respectively, with all three showing the highest values during periods when isoprene and MVK+MACR were also elevated. In our future work we will apply this data set to better understand the biogenic and anthropogenic processes controlling ambient FA, AA, and related species.

\section{The Supplement related to this article is available online at doi:10.5194/amt-8-1303-2015-supplement.}

Acknowledgements. This work was supported by the National Science Foundation (grants 1148951 and 0937004). Brent J. Williams acknowledges support from the US Environmental Protection Agency's STAR program (grant R835402). We thank the members of the ACT Lab at Washington University in St. Louis for their help during the SLAQRS field deployment. We also thank Timothy Griffis at the University of Minnesota Twin Cities for providing the $\mathrm{CO}_{2}$ standard and lending the dew point generator.

Edited by: C. Ammann

\section{References}

Akagi, S. K., Yokelson, R. J., Wiedinmyer, C., Alvarado, M. J., Reid, J. S., Karl, T., Crounse, J. D., and Wennberg, P. O.: Emission factors for open and domestic biomass burning for use in atmospheric models, Atmos. Chem. Phys., 11, 4039-4072, 2011, http://www.atmos-chem-phys.net/11/4039/2011/.

Andreae, M. O., Talbot, R. W., Andreae, T. W., and Harriss, R. C.: Formic and acetic-acid over the Central Amazon region, Brazil, 1. Dry season, J. Geophys. Res.-Atmos., 93, 1616-1624, 1988.

Atkinson, R., Baulch, D. L., Cox, R. A., Crowley, J. N., Hampson, R. F., Hynes, R. G., Jenkin, M. E., Rossi, M. J., and Troe, J.: Evaluated kinetic and photochemical data for atmospheric chemistry: Volume II - gas phase reactions of organic species, Atmos. Chem. Phys., 6, 3625-4055, doi:10.5194/acp-6-3625-2006, 2006. 
Beale, R., Dixon, J. L., Arnold, S. R., Liss, P. S., and Nightingale, P. D.: Methanol, acetaldehyde, and acetone in the surface waters of the Atlantic Ocean, J. Geophys. Res.-Oceans, 118, 5412-5425, 2013.

Beauchamp, J., Herbig, J., Dunkl, J., Singer, W., and Hansel, A.: On the performance of proton-transfer-reaction mass spectrometry for breath-relevant gas matrices, Meas. Sci. Technol., 24, 125003, doi:10.1088/0957-0233/24/12/125003, 2013.

Bertram, T. H., Kimmel, J. R., Crisp, T. A., Ryder, O. S., Yatavelli, R. L. N., Thornton, J. A., Cubison, M. J., Gonin, M., and Worsnop, D. R.: A field-deployable, chemical ionization timeof-flight mass spectrometer, Atmos. Meas. Tech., 4, 1471-1479, 2011 ,

http://www.atmos-meas-tech.net/4/1471/2011/.

Blake, R. S., Monks, P. S., and Ellis, A. M.: Proton-Transfer Reaction Mass Spectrometry, Chem. Rev., 109, 861-896, 2009.

Chebbi, A. and Carlier, P.: Carboxylic acids in the troposphere, occurrence, sources, and sinks: A review, Atmos. Environ., 30, 4233-4249, 1996.

Clair, J. M., Spencer, K. M., Beaver, M. R., Crounse, J. D., Paulot, F., and Wennberg, P. O.: Quantification of hydroxyacetone and glycolaldehyde using chemical ionization mass spectrometry, Atmos. Chem. Phys., 14, 4251-4262, 2014,

http://www.atmos-chem-phys.net/14/4251/2014/.

de Gouw, J. and Warneke, C.: Measurements of volatile organic compounds in the Earth's atmosphere using proton-transferreaction mass spectrometry, Mass Spectrom. Rev., 26, 223-257, 2007.

de Gouw, J. A., Goldan, P. D., Warneke, C., Kuster, W. C., Roberts, J. M., Marchewka, M., Bertman, S. B., Pszenny, A. A. P., and Keene, W. C.: Validation of proton transfer reaction-mass spectrometry (PTR-MS) measurements of gas-phase organic compounds in the atmosphere during the New England Air Quality Study (NEAQS) in 2002, J. Geophys. Res.-Atmos., 108, 4682, doi:10.1029/2003JD003863, 2003.

Dibble, T. S.: Intramolecular hydrogen bonding and double H-atom transfer in peroxy and alkoxy radicals from isoprene, J. Phys. Chem. A, 108, 2199-2207, 2004.

Dillon, T. J. and Crowley, J. N.: Direct detection of $\mathrm{OH}$ formation in the reactions of $\mathrm{HO}_{2}$ with $\mathrm{CH}_{3} \mathrm{C}(\mathrm{O}) \mathrm{O}_{2}$ and other substituted peroxy radicals, Atmos. Chem. Phys., 8, 4877-4889, 2008, http://www.atmos-chem-phys.net/8/4877/2008/.

Eerdekens, G., Ganzeveld, L., Vilà-Guerau de Arellano, J., Klüpfel, T., Sinha, V., Yassaa, N., Williams, J., Harder, H., Kubistin, D., Martinez, M., and Lelieveld, J.: Flux estimates of isoprene, methanol and acetone from airborne PTR-MS measurements over the tropical rainforest during the GABRIEL 2005 campaign, Atmos. Chem. Phys., 9, 4207-4227, doi:10.5194/acp-9-42072009, 2009.

Feilberg, A., Liu, D. Z., Adamsen, A. P. S., Hansen, M. J., and Jonassen, K. E. N.: Odorant emissions from intensive pig production measured by online proton-transfer-reaction mass spectrometry, Environ. Sci. Technol., 44, 5894-5900, 2010.

Fortner, E. C., Zheng, J., Zhang, R., Knighton, W. B., Volkamer, R. M., Sheehy, P., Molina, L., and Andre, M.: Measurements of volatile organic compounds using proton transfer reaction mass spectrometry during the MILAGRO 2006 campaign, Atmos. Chem. Phys., 9, 467-481, doi:10.5194/acp-9-467-2009, 2009.
Galloway, J. N., Likens, G. E., Keene, W. C., and Miller, J. M.: The composition of precipitation in remote areas of the world, J. Geophys. Res.-Oc. Atm., 87, 8771-8786, 1982.

Glasius, M., Boel, C., Bruun, N., Easa, L. M., Hornung, P., Klausen, H. S., Klitgaard, K. C., Lindeskov, C., Moller, C. K., Nissen, H., Petersen, A. P. F., Kleefeld, S., Boaretto, E., Hansen, T. S., Heinemeier, J., and Lohse, C.: Relative contribution of biogenic and anthropogenic sources to formic and acetic acids in the atmospheric boundary layer, J. Geophys. Res.-Atmos., 106, 74157426, 2001.

Good, D. A., Francisco, J. S., Jain, A. K., and Wuebbles, D. J.: Lifetimes and global warming potentials for dimethyl ether and for fluorinated ethers: $\mathrm{CH}_{3} \mathrm{OCF}_{3}(\mathrm{E} 143 \mathrm{a}), \mathrm{CHF}_{2} \mathrm{OCHF}_{2}$ (E134), $\mathrm{CHF}_{2} \mathrm{OCF}_{3}$ (E125), J. Geophys. Res.-Atmos., 103, 2818128186, 1998.

Grosjean, D.: Ambient levels of formaldehyde, acetaldehyde, and formic-acid in Southern California - results of a one-year baseline study, Environ. Sci. Technol., 25, 710-715, 1991.

Grosjean, D.: Formic-acid and acetic-acid - emissions, atmospheric formation and dry deposition at 2 Southern California locations, Atmos. Environ. A-Gen, 26, 3279-3286, 1992.

Haase, K. B., Keene, W. C., Pszenny, A. A. P., Mayne, H. R., Talbot, R. W., and Sive, B. C.: Calibration and intercomparison of acetic acid measurements using proton-transfer-reaction mass spectrometry (PTR-MS), Atmos. Meas. Tech., 5, 2739_ 2750, 2012,

http://www.atmos-meas-tech.net/5/2739/2012/.

Hatakeyama, S., Washida, N., and Akimoto, H.: Rate constants and mechanisms for the reaction of $\mathrm{OH}(\mathrm{OD})$ radicals with acetylene, propyne, and 2-butyne in air at $297+/-2 \mathrm{~K}$, J. Phys. Chem.-US, 90, 173-178, 1986.

Hu, L., Millet, D. B., Mohr, M. J., Wells, K. C., Griffis, T. J., and Helmig, D.: Sources and seasonality of atmospheric methanol based on tall tower measurements in the US Upper Midwest, Atmos. Chem. Phys., 11, 11145-11156, doi:10.5194/acp-1111145-2011, 2011.

Hu, L., Millet, D. B., Kim, S. Y., Wells, K. C., Griffis, T. J., Fischer, E. V., Helmig, D., Hueber, J., and Curtis, A. J.: North American acetone sources determined from tall tower measurements and inverse modeling, Atmos. Chem. Phys., 13, 33793392, doi:10.5194/acp-13-3379-2013, 2013.

Huey, L. G.: Measurement of trace atmospheric species by chemical ionization mass spectrometry: Speciation of reactive nitrogen and future directions, Mass Spectrom. Rev., 26, 166-184, 2007.

Hunter, E. P. L. and Lias, S. G.: Evaluated gas phase basicities and proton affinities of molecules: An update, J. Phys. Chem. Ref. Data, 27, 413-656, 1998.

Jardine, K., Yañez Serrano, A., Arneth, A., Abrell, L., Jardine, A., Artaxo, P., Alves, E., Kesselmeier, J., Taylor, T., Saleska, S., and Huxman, T.: Ecosystem-scale compensation points of formic and acetic acid in the central Amazon, Biogeosciences, 8, 37093720, doi:10.5194/bg-8-3709-2011, 2011.

Jordan, A., Haidacher, S., Hanel, G., Hartungen, E., Herbig, J., Mark, L., Schottkowsky, R., Seehauser, H., Sulzer, P., and Mark, T. D.: An online ultra-high sensitivity proton-transfer-reaction mass-spectrometer combined with switchable reagent ion capability (PTR+SRI-MS), Int. J. of Mass Spectrom., 286, 32-38, 2009. 
Jordan, C., Fitz, E., Hagan, T., Sive, B., Frinak, E., Haase, K., Cottrell, L., Buckley, S., and Talbot, R.: Long-term study of VOCs measured with PTR-MS at a rural site in New Hampshire with urban influences, Atmos. Chem. Phys., 9, 4677-4697, doi:10.5194/acp-9-4677-2009, 2009.

Karl, T., Potosnak, M., Guenther, A., Clark, D., Walker, J., Herrick, J. D., and Geron, C.: Exchange processes of volatile organic compounds above a tropical rain forest: Implications for modeling tropospheric chemistry above dense vegetation, J. Geophys. Res.-Atmos., 109, D18306, doi:10.1029/2004JD004738, 2004.

Keene, W. C. and Galloway, J. N.: Organic acidity in precipitation of North America, Atmos. Environ., 18, 2491-2497, 1984.

Keene, W. C., Galloway, J. N., and Holden, J. D.: Measurement of weak organic acidity in precipitation from remote areas of the world, J. Geophys. Res.-Oc. Atm., 88, 5122-5130, 1983.

Kesselmeier, J. and Staudt, M.: Biogenic volatile organic compounds (VOC): An overview on emission, physiology and ecology, J. Atmos. Chem., 33, 23-88, 1999.

Kesselmeier, J., Bode, K., Gerlach, C., and Jork, E. M.: Exchange of atmospheric formic and acetic acids with trees and crop plants under controlled chamber and purified air conditions, Atmos. Environ., 32, 1765-1775, 1998.

Kolb, C. E., Herndon, S. C., McManus, B., Shorter, J. H., Zahniser, M. S., Nelson, D. D., Jayne, J. T., Canagaratna, M. R., and Worsnop, D. R.: Mobile laboratory with rapid response instruments for real-time measurements of urban and regional trace gas and particulate distributions and emission source characteristics, Environ. Sci. Technol., 38, 5694-5703, 2004.

Le Breton, M., McGillen, M. R., Muller, J. B. A., Bacak, A., Shallcross, D. E., Xiao, P., Huey, L. G., Tanner, D., Coe, H., and Percival, C. J.: Airborne observations of formic acid using a chemical ionization mass spectrometer, Atmos. Meas. Tech., 5, 30293039, 2012, http://www.atmos-meas-tech.net/5/3029/2012/.

Le Breton, M., Bacak, A., Muller, J. B. A., Xiao, P., Shallcross, B. M. A., Batt, R., Cooke, M. C., Shallcross, D. E., Bauguitte, S. J. B., and Percival, C. J.: Simultaneous airborne nitric acid and formic acid measurements using a chemical ionization mass spectrometer around the UK: Analysis of primary and secondary production pathways, Atmos. Environ., 83, 166-175, 2014.

Lee, A., Goldstein, A. H., Kroll, J. H., Ng, N. L., Varutbangkul, V., Flagan, R. C., and Seinfeld, J. H.: Gas-phase products and secondary aerosol yields from the photooxidation of 16 different terpenes, J. Geophys. Res.-Atmos., 111, D17305, doi:10.1029/2006JD007050, 2006a.

Lee, J. H., Hopke, P. K., and Turner, J. R.: Source identification of airborne PM2.5 at the St. Louis-Midwest Supersite, J. Geophys. Res.-Atmos., 111, D10S10, doi:10.1029/2005JD006329, $2006 \mathrm{~b}$.

Lindinger, W., Hansel, A., and Jordan, A.: On-line monitoring of volatile organic compounds at pptv levels by means of protontransfer-reaction mass spectrometry (PTR-MS) - Medical applications, food control and environmental research, Int. J. of Mass Spectrom., 173, 191-241, 1998.

Park, J. H., Goldstein, A. H., Timkovsky, J., Fares, S., Weber, R., Karlik, J., and Holzinger, R.: Active atmosphere-ecosystem exchange of the vast majority of detected volatile organic compounds, Science, 341, 643-647, 2013.

Paulot, F., Crounse, J. D., Kjaergaard, H. G., Kroll, J. H., Seinfeld, J. H., and Wennberg, P. O.: Isoprene photooxidation: new insights into the production of acids and organic nitrates, Atmos. Chem. Phys., 9, 1479-1501, doi:10.5194/acp-9-1479-2009, 2009.

Paulot, F., Wunch, D., Crounse, J. D., Toon, G. C., Millet, D. B., DeCarlo, P. F., Vigouroux, C., Deutscher, N. M., González Abad, G., Notholt, J., Warneke, T., Hannigan, J. W., Warneke, C., de Gouw, J. A., Dunlea, E. J., De Mazière, M., Griffith, D. W. T., Bernath, P., Jimenez, J. L., and Wennberg, P. O.: Importance of secondary sources in the atmospheric budgets of formic and acetic acids, Atmos. Chem. Phys., 11, 1989-2013, doi:10.5194/acp-11-1989-2011, 2011.

Roberts, J. M., Veres, P., Warneke, C., Neuman, J. A., Washenfelder, R. A., Brown, S. S., Baasandorj, M., Burkholder, J. B., Burling, I. R., Johnson, T. J., Yokelson, R. J., and de Gouw, J.: Measurement of HONO, HNCO, and other inorganic acids by negative-ion proton-transfer chemical-ionization mass spectrometry (NI-PT-CIMS): application to biomass burning emissions, Atmos. Meas. Tech., 3, 981-990, doi:10.5194/amt-3-981-2010, 2010.

Roberts, J. M., Veres, P. R., Cochran, A. K., Warneke, C., Burling, I. R., Yokelson, R. J., Lerner, B., Gilman, J. B., Kuster, W. C., Fall, R., and de Gouw, J.: Isocyanic acid in the atmosphere and its possible link to smoke-related health effects, P. Natl. Acad. Sci. USA, 108, 8966-8971, 2011.

Schnitzhofer, R., Wisthaler, A., and Hansel, A.: Real-time profiling of organic trace gases in the planetary boundary layer by PTRMS using a tethered balloon, Atmos. Meas. Tech., 2, 773-777, doi:10.5194/amt-2-773-2009, 2009.

Spanel, P., Diskin, A. M., Wang, T., and Smith, D.: A SIFT study of the reactions of $\mathrm{H}_{3} \mathrm{O}^{+}, \mathrm{NO}^{+}$and $\mathrm{O}_{2}^{+}$with hydrogen peroxide and peroxyacetic acid, Int. J. of Mass Spectrom., 228, 269-283, 2003.

Stavrakou, T., Muller, J. F., Peeters, J., Razavi, A., Clarisse, L., Clerbaux, C., Coheur, P. F., Hurtmans, D., De Maziere, M., Vigouroux, C., Deutscher, N. M., Griffith, D. W. T., Jones, N., and Paton-Walsh, C.: Satellite evidence for a large source of formic acid from boreal and tropical forests, Nat. Geosci., 5, 2630, 2012.

Talbot, R. W., Beecher, K. M., Harriss, R. C., and Cofer, W. R.: Atmospheric geochemistry of formic and acetic acids at a midlatitude temperate site, J. Geophys. Res.-Atmos., 93, 1638-1652, 1988.

Talbot, R. W., Dibb, J. E., Scheuer, E. M., Blake, D. R., Blake, N. J., Gregory, G. L., Sachse, G. W., Bradshaw, J. D., Sandholm, S. T., and Singh, H. B.: Influence of biomass combustion emissions on the distribution of acidic trace gases over the southern Pacific basin during austral springtime, J. Geophys. Res.-Atmos., 104, 5623-5634, 1999.

Veres, P., Roberts, J. M., Warneke, C., Welsh-Bon, D., Zahniser, M., Herndon, S., Fall, R., and de Gouw, J.: Development of negativeion proton-transfer chemical-ionization mass spectrometry (NIPT-CIMS) for the measurement of gas-phase organic acids in the atmosphere, Int. J. Mass Spectrom., 274, 48-55, 2008.

Veres, P., Gilman, J. B., Roberts, J. M., Kuster, W. C., Warneke, C., Burling, I. R., and de Gouw, J.: Development and validation of a portable gas phase standard generation and calibration system for volatile organic compounds, Atmos. Meas. Tech., 3, 683-691, doi:10.5194/amt-3-683-2010, 2010.

Veres, P. R., Roberts, J. M., Cochran, A. K., Gilman, J. B., Kuster, W. C., Holloway, J. S., Graus, M., Flynn, J., Lefer, B., Warneke, 
C., and de Gouw, J.: Evidence of rapid production of organic acids in an urban air mass, Geophys. Res. Lett., 38, L17807, doi:10.1029/2011GL048420, 2011.

Wang, G. L., Hopke, P. K., and Turner, J. R.: Using highly time resolved fine particulate compositions to find particle sources in St. Louis, MO, Atmos. Pollut. Res., 2, 219-230, 2011.

Wang, M., Zhu, T., Zheng, J., Zhang, R. Y., Zhang, S. Q., Xie, X. X., Han, Y. Q., and Li, Y.: Use of a mobile laboratory to evaluate changes in on-road air pollutants during the Beijing 2008 Summer Olympics, Atmos. Chem. Phys., 9, 8247-8263, doi:10.5194/acp-9-8247-2009, 2009.

Warneke, C., van der Veen, C., Luxembourg, S., de Gouw, J. A., and Kok, A.: Measurements of benzene and toluene in ambient air using proton-transfer-reaction mass spectrometry: calibration, humidity dependence, and field intercomparison, Int. J. Mass Spectrom., 207, 167-182, 2001.

Warneke, C., de Gouw, J. A., Goldan, P. D., Kuster, W. C., Williams, E. J., Lerner, B. M., Jakoubek, R., Brown, S. S., Stark, H., Aldener, M., Ravishankara, A. R., Roberts, J. M., Marchewka, M., Bertman, S., Sueper, D. T., McKeen, S. A., Meagher, J. F., and Fehsenfeld, F. C.: Comparison of daytime and nighttime oxidation of biogenic and anthropogenic VOCs along the New England coast in summer during New England Air Quality Study 2002, J. Geophys. Res.-Atmos., 109, D10309, doi:10.1029/2003JD004424, 2004.
Williams, J., Holzinger, R., Gros, V., Xu, X., Atlas, E., and Wallace, D. W. R.: Measurements of organic species in air and seawater from the tropical Atlantic, Geophys. Res. Lett., 31, L23S06, doi:10.1029/2004GL020012, 2004.

Yokelson, R. J., Crounse, J. D., DeCarlo, P. F., Karl, T., Urbanski, S., Atlas, E., Campos, T., Shinozuka, Y., Kapustin, V., Clarke, A. D., Weinheimer, A., Knapp, D. J., Montzka, D. D., Holloway, J., Weibring, P., Flocke, F., Zheng, W., Toohey, D., Wennberg, P O., Wiedinmyer, C., Mauldin, L., Fried, A., Richter, D., Walega, J., Jimenez, J. L., Adachi, K., Buseck, P. R., Hall, S. R., and Shetter, R.: Emissions from biomass burning in the Yucatan, Atmos. Chem. Phys., 9, 5785-5812, doi:10.5194/acp-9-5785-2009, 2009. 